(2) Open Access Full Text Article

REVIEW

\title{
New approaches in the management of multiple sclerosis
}

This article was published in the following Dove Press journal:

Drug Design, Development and Therapy

22 November 2010

Number of times this article has been viewed

\author{
Laurie J Barten' \\ Douglas R Allington' \\ Kendra A Procacci ${ }^{2}$ \\ Michael P Rivey' \\ 'The University of Montana \\ and Community Medical Center, \\ Missoula, MT, USA; ${ }^{2}$ The University \\ of Montana School of Pharmacy, \\ Missoula, MT, USA
}

\begin{abstract}
Multiple sclerosis (MS) is a central nervous system chronic inflammatory disease that is characterized by an extensive and complex immune response. Scientific advances have occurred in immunology, pathophysiology, and diagnostic and clinical assessment tools, and recent discovery of unique therapeutic targets has spurred numerous Phase II and Phase III clinical trials. Reductions in MS relapse rates and improvements in $\mathrm{T}_{2}$ or gadolinium-enhancing lesion burdens have been reported from Phase III trials that include fingolimod, alemtuzumab, cladribine, and rituximab. Promising Phase II trial data exist for teriflunomide, daclizumab, laquinimod, and fumarate. The optimism created by these favorable findings must be tempered with evaluation of the adverse effect profile produced by these new agents. Given the discovery of progressive multifocal leukoencephalopathy with the use of natalizumab, ongoing vigilance for rare and life-threatening reactions due to new agents should be paramount. Patients with MS often experience difficulty with ambulation, spasticity, and cognition. Recent clinical trial data from two Phase III dalfampridine-SR trials indicate certain patients receive benefits in ambulation. This article provides an overview of data from clinical trials of newer agents of potential benefit in MS.
\end{abstract}

Keywords: multiple sclerosis, Phase II trials, Phase III trials, progressive multifocal leukoencephalopathy, monoclonal antibody

\section{Introduction}

Multiple sclerosis (MS) is a chronic inflammatory disease associated with central nervous system (CNS) demyelination. MS exhibits an unpredictable and variable clinical course, making treatment challenging. Discoveries in immunology, magnetic resonance imaging (MRI) and diagnostics, early treatment options, and development of biological agents have improved the prospects for many MS patients. This article discusses recent advances in MS immunology, current and experimental therapies, and future targets for drug development.

\section{Epidemiology}

MS is typically diagnosed in the third or fourth decade of life with only $5 \%-10 \%$ of disease onset occurring in individuals aged less than 10 or more than 50 years old. ${ }^{1}$ Women are affected approximately twice as often as males who are more likely diagnosed later in life and have a progressive course of disease. Individuals living further from the equator are more commonly affected, with people living in Europe, southern Australia, and the middle of North America at greatest risk. ${ }^{1-3}$ The criteria for diagnosing MS have undergone significant revisions over the last decade. The revised McDonald criteria
Correspondence: Douglas R Allington

The University of Montana and

Community Medical Center,

Missoula, MT, USA

Email douglas.allington@umontana.edu 
(2005) has generally replaced the older Schumacher and Poser criteria. ${ }^{4,5}$ McDonald criteria include clinical, paraclinical, and laboratory evidence of demyelinating inflammatory lesions disseminated in space and time. MRI, cerebrospinal fluid analysis, and visual-evoked potentials assist in diagnosis. A consensus statement by an international panel of experts includes guidelines for differential diagnosis of MS and clinically isolated syndrome (CIS). ${ }^{6}$

A first episode of a neurological sign or symptom consistent with MS, caused by demyelination, is defined as a CIS. Optic nerve dysfunction, diplopia, bladder and bowel dysregulation, ataxia, limb sensory dysfunction, and pyramidal tract abnormalities represent some hallmark CIS signs and symptoms. ${ }^{7}$ CIS patients with concurrent MRI abnormalities are at higher risk for eventually acquiring the diagnosis of clinically definite multiple sclerosis. ${ }^{8}$ Several major placebocontrolled clinical trials, ETOM, ${ }^{9}$ CHAMPS,${ }^{10}$ BENEFIT, ${ }^{11}$ and PreCISe, ${ }^{12}$ have shown that interferon (IFN) $\beta$-1a $\left(\right.$ Rebif $^{\circledR}$; EMD Serono, Inc., Rockland, MA, USA) (Avonex ${ }^{\circledR}$; Biogen Idec, Cambridge, MA, USA), IFN $\beta$-1b (Betaseron ${ }^{\circledR}$; Bayer Healthcare Pharmaceuticals, Inc., Montville, NJ, USA), or glatiramer acetate (Copaxone ${ }^{\circledR}$; TEVA Neuroscience, Inc., Kansas City, MO, USA) therapy in CIS patients postpones the time to clinically definite multiple sclerosis for some. A 3-year extension of the BENEFIT ${ }^{13}$ study and a 5-year extension of the CHAMPS study, CHAMPION, ${ }^{14}$ have confirmed benefits of early treatment.

MS typically follows a relapsing and remitting course in its early stages; patients experience symptomatic attacks or exacerbations, which occur for a period of time and then resolve. This presentation occurring in $80 \%-85 \%$ of patients is classified as relapsing-remitting multiple sclerosis (RRMS). ${ }^{1-3}$ The typical course for RRMS includes initial stages of relapse with full or partial recovery, then relapse with persistent deficit, and eventually secondary progressive disease (Figure 1). ${ }^{3}$ Approximately $50 \%$ of individuals diagnosed with RRMS will enter a secondary progressive MS (SPMS) phase after 10 years, ${ }^{15}$ whereas $15 \%-20 \%$ of patients will experience the primary progressive form of MS (PPMS) at onset.

Prognosis in MS varies significantly. Approximately $10 \%$ of patients function well for 20 or more years. ${ }^{2}$ However, death occurs within months in rare cases of PPMS. ${ }^{3}$ Life expectancy after diagnosis is $\sim 25$ years, and most patients die of other causes. ${ }^{3}$ Patients with optic neuritis, brain-stem dysfunction, incomplete transverse myelitis, and motor involvement with gait and coordination dysfunction have a more negative prognosis. In contrast, patients with sensory or visual symptoms as a dominant neurological sign have a more

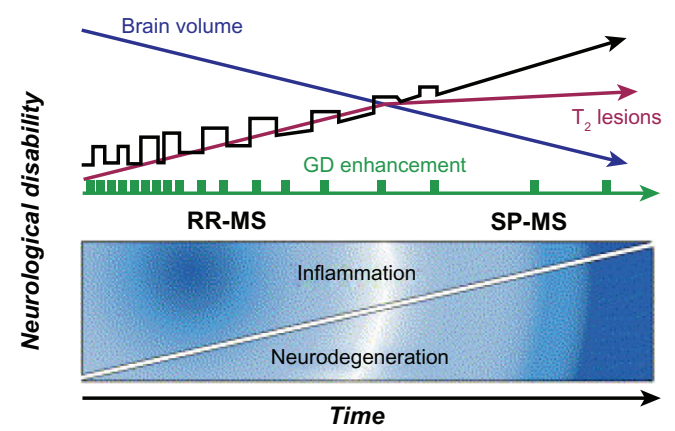

Figure I Natural history of MS. Four clinical patterns are recognized by international consensus. Approximately $85 \%$ of patients experience RRMS, characterized by the abrupt start of symptoms and acute episodes of worsening (exacerbations or relapses) with complete or partial recovery. Between these episodes, patients may be clinically stable, may experience gradual progression of disability, or may undergo a combination of both. Approximately $50 \%$ of patients with RRMS convert to SPMS within 10 years of disease onset. The secondary progressive phase is characterized by gradual progression of disability with or without superimposed relapses. In contrast, patients with PPMS ( $10 \%$ of patients with MS) experience gradual progression of disability from onset without superimposed relapses. Patients with progressive relapsing MS experience gradual progression of disability from disease onset, later accompanied by one or more relapses; this clinical pattern affects $\sim 5 \%$ of patients. An important conceptual development in the understanding of MS pathogenesis has been the compartmentalization of the mechanistic process into two distinct but overlapping and connected phases, inflammatory and neurodegenerative. Axonal loss begins most likely at disease onset and accumulates. Conversion of relapsingremitting to secondary progressive occurs once axon loss surpasses the capacity of the CNS to compensate for loss of function. Copyright (C) 2006, Elsevier. Adapted with permission from Hauser SL, Oksenberg JR. The neurobiology of multiple sclerosis: genes, inflammation, and neurodegeneration. Neuron. 2006;52(I):6I-76. ${ }^{15}$ Abbreviations: CNS, central nervous system; RRMS, relapsing-remitting multiple sclerosis; SPMS, secondary progressive multiple sclerosis; PPMS, primary progressive multiple sclerosis.

positive prognosis. Women, younger patients, and those with RRMS disease who experience a more complete recovery after exacerbations have a better prognosis, whereas patients with PPMS fare worse. ${ }^{2,5}$ Discussed as early as the $1950 \mathrm{~s},{ }^{16}$ data from recent epidemiological studies suggest pregnancy has a 'protective' effect resulting in fewer MS relapses. It was hypothesized that increased estrogen levels that are normal during pregnancy modulate MS response.

\section{Quality of life measures/clinical assessment tools}

Several validated assessment instruments have been used to document MS baseline disability and disease progression. The Expanded Disability Status Scale (EDSS) was introduced in 1983 and yields scores ranging from 0 (normal neurological exam) to 10 (death) in 0.5 numeric increments. EDSS scores $<3.0,3.0-5.0$, and $>5.0$ represent mild, moderate, and severe disability, respectively. Important limitations associated with the EDSS include the need for physicians to administer the test, nonlinear scores, rater subjectivity at EDSS scores less than 3, and excessive weighting of ambulation versus cognition and upper extremity function. ${ }^{17}$ 
The Multiple Sclerosis Functional Composite (MSFC) assessment tool was developed in 1994 by a National Multiple Sclerosis Society task force. The MSFC tests upper extremity dexterity with a timed nine-hole peg test, timed walking speed over 25 feet, and cognition via Paced Auditory Serial Addition Test (PASAT). The MSFC has demonstrated construct validity among different MS patient populations and concurrent validity with EDSS scores and MRI findings. ${ }^{17}$

Outcome measures in most MS clinical trials include relapse rates, appearance of new or expansion of existing lesions, or change in other surrogate markers of inflammation. Historically, health-related quality of life measures were ignored or given secondary consideration, and few clinical trials were 'powered' to detect significant differences in health-related quality of life measures. Medical Outcomes Study Short Form-36, Functional Status Questionnaire, and the Sickness Impact Profile are some of the instruments used in MS studies. These general instruments have broad applicability, making comparison possible to other individuals with serious medical illnesses. Multiple Sclerosis Quality of Life Inventory, Multiple Sclerosis Quality of Life-54, Functional Assessment of Multiple Sclerosis, Leeds Multiple Sclerosis Quality of Life scale, and Multiple Sclerosis Impact Scale-29 are reliable and validated instruments specific for MS. Miller et al have recently completed an excellent review of the advantages and disadvantages of these MS instruments. ${ }^{18}$

\section{Pathogenesis}

MS plaques result from an altered immune response initiated in the periphery but ultimately manifested on myelin, glial cells, dendrites, and axons of the CNS. The exact etiology of MS is unknown, but evidence suggests an environmental trigger in a genetically susceptible individual leads to an altered immune response directed against self that results in inflammation, demyelination, neurodegeneration, and dysfunctional neuronal repair. Immunologic responses in MS are characterized by an intricate and extensive cascade of events. Much of our understanding of processes that initiate altered immune response, myelin destruction, chronic axonal damage, and dysfunctional repair in MS has been elucidated by use of animal models. Experimental autoimmune encephalopathy (EAE) and mice knockout models, which share similarities to MS in humans, have played an essential role in unraveling elements of the immunologic cascade. ${ }^{19}$ Various animal models exist that express similarities to human diseases of optic neuritis ${ }^{20}$ RRMS, and chronic progressive
MS. ${ }^{21}$ Gold et al have recently completed an excellent review article documenting seven decades of animal model use in MS research. ${ }^{22}$

Undoubtedly, critical information will continue to be gleaned from ongoing work with animal models. However, many scientists and practitioners believe that new biomarkers from individuals with MS are required. New biomarkers should be sought to aid in prognosis or augment existing means of patient stratification prior to entry in novel clinical trials. ${ }^{23}$

Over the past 50 years, numerous viruses have been implicated as the 'infectious' component for initiating the inflammatory responses typical of MS in genetically predisposed patients. At various times, herpes simplex viruses 1 or 2, cytomegalovirus, measles, mumps, rubella, and Epstein-Barr virus have been promoted as candidates. The viral infection theory involves nuanced discussions related to geographical variation, 'hygiene' hypothesis, cerebrospinal fluid titers, viral reactivation and MS exacerbations, and immunoassay limitations that are beyond the scope of this review. The potential role of infection in MS has recently been reviewed. ${ }^{24}$

Clustering of MS in families and certain ethnic groups and results from monozygotic and dizygotic twin studies provide evidence of a genetic link. Linkage studies have identified the human leukocyte antigen class II locus in the major histocompatibility complex (MHC) region on chromosome $6 \mathrm{p} 21$ as being significant but accounting for only a portion of MS susceptibility. ${ }^{25}$ Sophisticated mapping techniques of MS patients using single nucleotide polymorphisms in genes have identified additional MS susceptibility associated with a gene encoding a subunit of high-affinity interleukin-2 receptor (IL2RA), also known as CD25, and possibly genes for IL-7 receptor (IL7R). ${ }^{26}$ Oksenberg and colleagues have published an excellent review of this topic. ${ }^{27}$ Data mining of extensive brain plaque libraries from MS patients, compared to data from normal controls, have yielded other important areas of investigation. Such comparisons have led to investigations of osteopontin (OPN), myelin basic protein (MBP), IFN- $\gamma$, and IL-12. ${ }^{28}$

\section{Pathophysiology}

Molecular mimicry or bystander activation are two popular theories used to explain how environmental triggers lead to altered autoimmunity. ${ }^{29}$ Molecular mimicry involves viral pathogens or other foreign antigens that share antigenic determinants similar to host cells triggering T-cell activation. ${ }^{28}$ Numerous proteins from herpes, measles, influenza, and 
other viruses share amino acid homologies to MBP, making them attractive candidates as mimics. ${ }^{15}$ Bystander activation postulates viral or bacterial infections cause tissue destruction exposing self-antigens. These self-antigens in the presence of cytokines, chemokines, or interleukins lead to enhanced antigen cell presentation, T-cell activation and proliferation, with subsequent, targeted response to MBP, proteolipid protein, and myelin oligodendrocyte glycoprotein (MOG). ${ }^{29}$ Whether initiated by a molecular mimic or exposure of autoantigens, the subsequent altered response of the immune system in MS is complex. The complexity of response in MS can, in part, be described by events that occur in the peripheral compartment, cellular migration across the blood-brain barrier (BBB), and events isolated within the CNS. Another layer of complexity of MS results from the activation and interaction of the innate and adapted immune systems. Paramount events in the periphery consist of T-cell activation, tethering, rolling, and adhesion, facilitated by integrin expression on activated $\mathrm{T}$ cells and interaction with its upregulated ligand vascular cellular adhesion molecule-1 (VCAM-1), expressed on the endothelium of blood vessels of the CNS. T-cell transmigration across the BBB and further trafficking within the CNS are aided by matrix metalloproteinases. Numerous immune and antibody-mediated events occur in the CNS. Astrocytes, microglia, and macrophages act as antigenpresenting cells that, along with MHC proteins, process MS antigen generating $\mathrm{CD} 4{ }^{+}$effector $\mathrm{T}$ cells capable of expressing Th1 or Th2 cell phenotypes. Subsequent exposure to tumor necrosis factor- $\alpha$ (TNF- $\alpha$ ), IFN- $\gamma$, or other costimulants causes restricted cytotoxic $\mathrm{CD}^{+} \mathrm{T}$-cell upregulation. Th2 cells, under the influence of various interleukins, can activate B cells that initiate antibody production directed against host tissue (see Figure 2).

Considerable heterogeneity of cellular components from active MS lesions exists, and a classification scheme of four distinct lesion patterns has been developed. This classification scheme proposes that MS shifts from an initial autoinflammatory disease driven by cellular and humoral abnormalities (Patterns I and II) to one dominated by lack of B- and T-cell infiltration, apoptosis, ischemia, primary glial damage, and sparse remyelination (Patterns III and IV) (see Figure 3). Conceptually, this classification scheme helps categorize complex immunological responses, serves to identify potential therapeutic targets, and may help to explain progression from RRMS to SPMS. However, others point out that rigorous, static classification schemes fail to accurately account for MS patients who present with multiples lesions in different phases. ${ }^{30}$

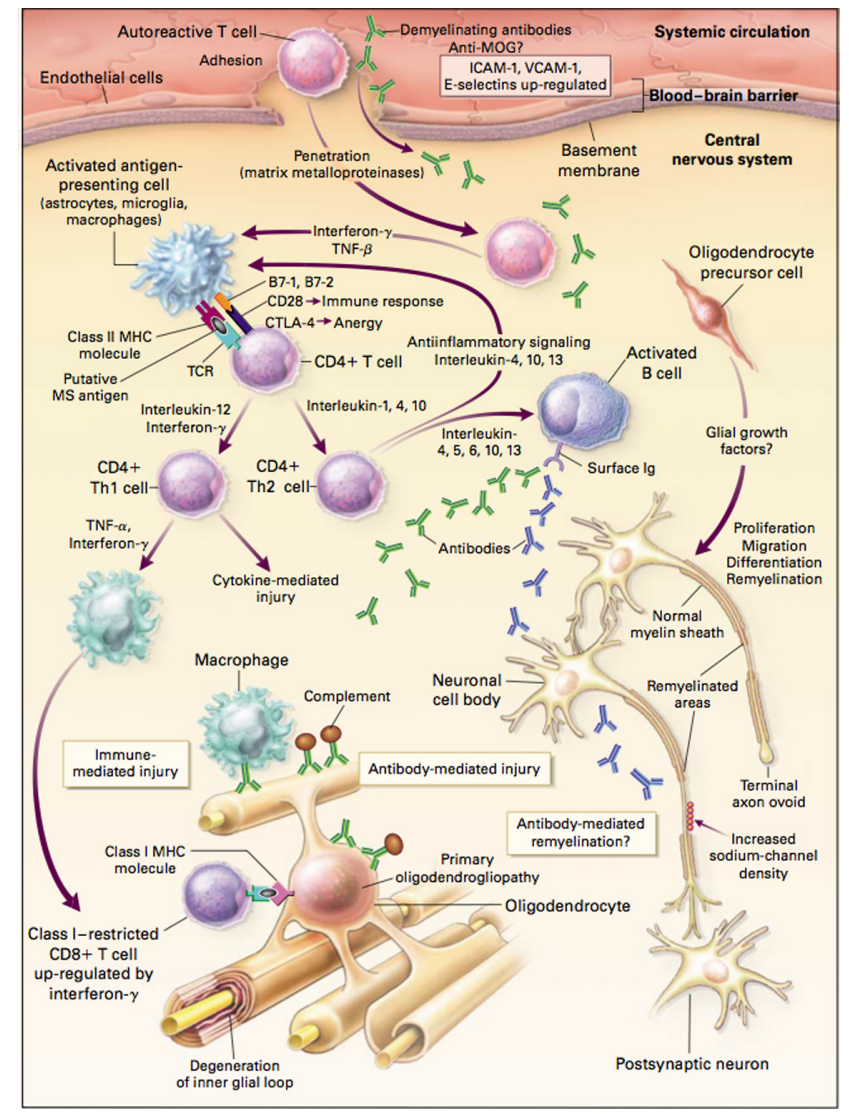

Figure 2 Possible mechanisms of injury and repair in MS. Genetic and environmental factors (including viral infection, bacterial lipopolysaccharides, superantigens, reactive metabolites, and metabolic stress) may facilitate the movement of autoreactive $\mathrm{T}$ cells and demyelinating antibodies from the systemic circulation into the CNS through disruption of the BBB. In the CNS, local factors (including viral infection and metabolic stress) may upregulate the expression of endothelial adhesion molecules, such as ICAM-I, VCAM-I, and E-selectin, further facilitating the entry of T cells into the CNS. Proteases, including matrix metalloproteinases, may further enhance the migration of autoreactive immune cells by degrading extracellularmatrix macromolecules. Proinflammatory cytokines released by activated $\mathrm{T}$ cells, such as IFN- $\gamma$ and TNF- $\beta$, may upregulate the expression of cell-surface molecules on neighboring lymphocytes and antigen-presenting cells. Binding of putative MS antigens, such as myelin basic protein, myelin-associated glycoprotein, MOG, proteolipid protein, $\alpha \beta$-crystallin, phosphodiesterases, and S-100 protein, by the trimolecular complex - the TCR and class II MHC molecules on antigen-presenting cells - may trigger either an enhanced immune response against the bound antigen or anergy, depending on the type of signaling that results from interactions with surface costimulatory molecules (eg, CD28 and CTLA-4) and their ligands (eg, B7-I and B7-2). Downregulation of the immune response (anergy) may result in the release of anti-inflammatory cytokines (IL-I, IL-4, and IL-I0) from CD4 ${ }^{+} \mathrm{T}$ cells, leading to the proliferation of anti-inflammatory CD4+ Th2 cells. Th2 cells may send anti-inflammatory signals to the activated antigen-presenting cells and stimulate pathologic or repair-enhancing antibody-producing B cells. Alternatively, if antigen processing results in an enhanced immune response, proinflammatory cytokines (eg, IL-I 2 and IFN- $\gamma$ ) may trigger a cascade of events, resulting in the proliferation of proinflammatory $\mathrm{CD}^{+}$ThI cells and ultimately in immune-mediated injury to myelin and oligodendrocytes. Multiple mechanisms of immune-mediated injury of myelin have been postulated: cytokine-mediated injury of oligodendrocytes and myelin; digestion of surface myelin antigens by macrophages, including binding of antibodies against myelin and oligodendrocytes (ie, antibody-dependent cytotoxicity); complement-mediated injury; and direct injury of oligodendrocytes by $\mathrm{CD} 4^{+}$and $\mathrm{CD}^{+} \mathrm{T}$ cells. This injury to the myelin membrane results in denuded axons that are no longer able to transmit action potentials efficiently within the CNS (loss of saltatory conduction). This slowing or blocking of the action potential results in the production of neurologic symptoms. The exposed axon segments may be susceptible to further injury from soluble mediators of injury (including cytokines, chemokines, complement, and proteases), resulting in irreversible axonal injury (such as axonal transection and terminal axon ovoids). There are several possible mechanisms of 
repair of the myelin membrane, including resolution of the inflammatory response followed by spontaneous remyelination, spread of sodium channels from the nodes of Ranvier to cover denuded axon segments and restore conduction, antibody-mediated remyelination, and remyelination resulting from the proliferation, migration, and differentiation of resident oligodendrocyte precursor cells.

Copyright (c) 2000, Massachusetts Medical Society. All rights reserved. Adapted with permission from Noseworthy JH, Lucchinetti C, Rodriguez M, Weinshenker BG. Multiple sclerosis. N Engl J Med. 2000;343(I3):938-952. ${ }^{2}$

Abbreviations: ICAM-I, intercellular adhesion molecule I; VCAM-I, vascular-cell adhesion molecule I; CNS, central nervous system; TNF- $\beta$, tumor necrosis factor- $\beta$; MOG, myelin oligodendrocyte glycoprotein; MS, multiple sclerosis; TCR, T-cell receptor; MHC, major-histocompatibility-complex; ThI, type I helper T; Th2, type 2 helper T; BBB, blood-brain barrier.

\section{Immunologic targets}

Antigen processing in the peripheral compartment is responsible for antibody production within peripheral lymph nodes. Trapping activated $\mathrm{T}$ cells within lymph nodes would prevent lymphocyte egress and their subsequent transmigration to the CNS. Spingosine-1-phosphate (S1P1) receptors on lymphocytes are responsible for egress from peripheral lymph nodes. Fingolimod (FTY720) (Gilenia ${ }^{\circledR}$; Biogen Idec, Cambridge, MA, USA) is a reversible S1P1 antagonist that has shown benefits in reducing relapse rates in RRMS patients. $^{31}$

Integrins are a superfamily of molecules that assist lymphocyte trafficking from peripheral cells to numerous target organs. Each integrin has one or more corresponding ligands, and specificity for trafficking is determined by this partnership. $\alpha 4 \beta 1$ integrin is specific to CNS endothelium, and antagonism in EAE animal models led to blunted lymphocyte migration and improved clinical course of EAE. ${ }^{32}$ Natalizumab (Tysarbi ${ }^{\circledR}$; Elan Pharmaceuticals, Inc., South San Francisco, CA, USA) is a monoclonal antibody directed at $\alpha 4 \beta 1$ integrin that has shown substantial activity at suppressing relapse rates in MS patients. ${ }^{33}$

During research to record the cognate receptors for the superfamily of integrins, OPN was discovered to bind to $\alpha 4 \beta 1$ integrin. ${ }^{34}$ OPN enhances Th1- and Th17-type cytokine responses in dendritic cells in EAE models and in MS. ${ }^{35,36}$ OPN has pleotrophic effects in various animal models, capable of inducing relapse remission in $\mathrm{SJL} / \mathrm{J}$ mice but also blunting recovery and promoting disease progression in another animal model, C57BL/6 mice. ${ }^{37}$ Data obtained during human transcription gene studies comparing mRNA from 11,000 patients with MS versus results from normal brain tissue identified $\alpha \beta$-crystallin as the most commonly transcribed gene while OPN was the fifth. ${ }^{38}$ Astrocytes and microglial cells can express OPN,${ }^{38}$ and up regulated expression of OPN has been described by others in normal-appearing white matter of MS. ${ }^{39}$ Data from emerging research indicate that OPN regulates coagulation proteins such as fibronectin, serpin A5,

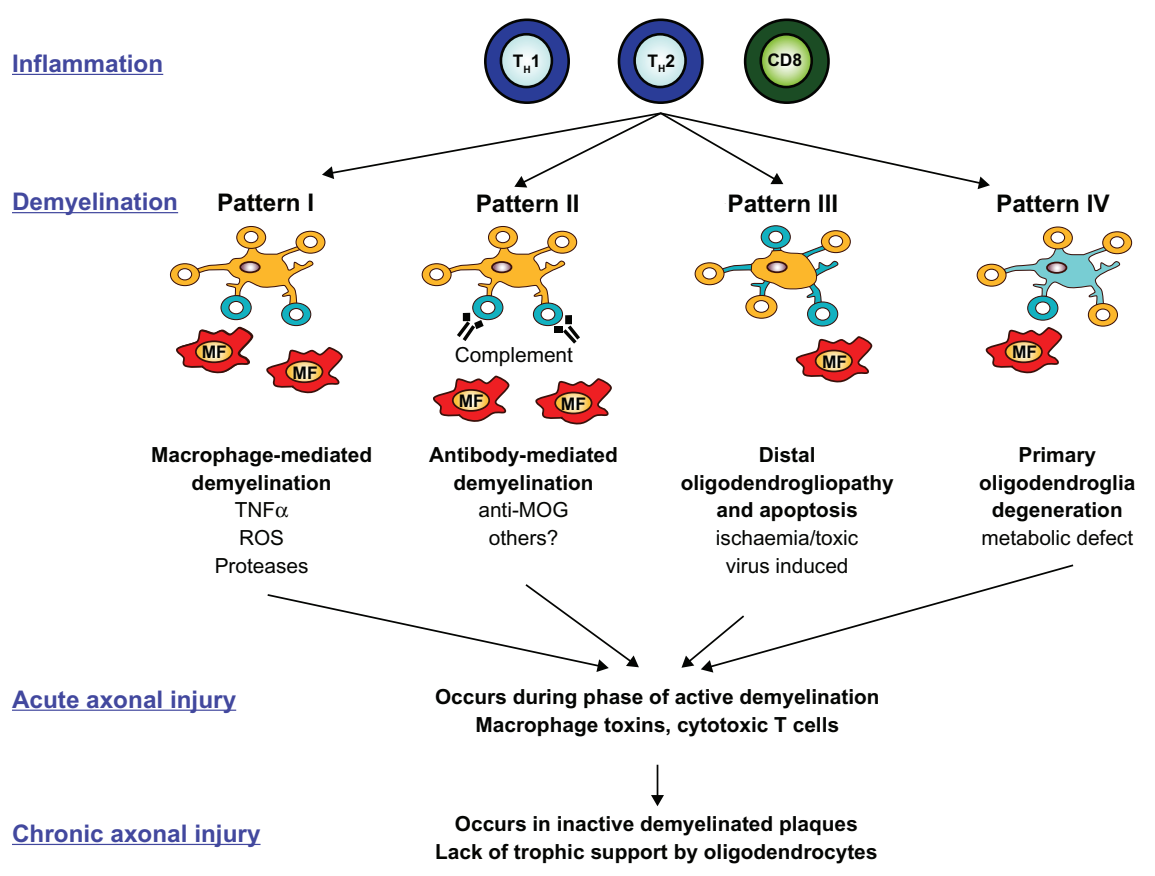

Figure 3 Classification of MS lesion pattern. Various cellular (macrophages and activated microglia) and humoral (antibodies and complement) immune components are dominating in Pattern I and II lesions. In contrast, Pattern III and IV are mainly characterized by a primary oligodendropathy with less inflammation. Type III lesions barely remyelinate and are similar to lesions found after hypoxic and/or toxic brain injury. Type IV lesions differ from lesion Pattern III by increased oligodendrocyte apoptosis due to metabolic dysfunction.

Copyright (C) 2007, Bentham Science Publishers. Adapted with permission from Kleinschnitz C, MEuth SG, Kieseier BC, Wiendl H. Immunotherapeutic approaches in MS: update on pathophysiology and emerging agents or strategies 2006. Endocr Metab Immune Disord Drug Targets. 2007;7(I):35-63. ${ }^{128}$

Abbreviations: CD8, CD8 T cell; MF, macrophage; MOG, myelin oligodendrocyte glycoprotein; ROS, reactive oxygen species; T, T cell; TNF, tumor necrosis factor. 
tissue factor, and thrombospondin. These coagulation proteins and others have been isolated from MS lesions. ${ }^{40}$ Thrombin has been shown to cleave OPN, which subsequently exposes additional $\alpha 4 \beta 1$ integrin binding sites. ${ }^{34}$

$\alpha \beta$-Crystallin is a member of the superfamily of small heat shock proteins. These proteins serve as molecular chaperones helping to maintain cellular homeostasis. Research in both relapsing-remitting and chronic progressive EAE models has shown $\alpha \beta$-crystallin aids in reducing generation of Th1 and Th17 cytokines by myelin specific T cells. Pretreatment with recombinant $\alpha \beta$-crystallin protected glial cells, lowered clinical disease scores, and modified paralysis in EAE. ${ }^{41}$

CNS tissue destruction of myelin and axons is accomplished through several different antibody-dependent processes, cell-mediated toxic pathways, complements, and macrophages. ${ }^{15}$ Autoantibodies directed against myelin oligodendrocyte glycoprotein, MBP, and proteolipid protein have been found in cerebral spinal fluid of MS patients. ${ }^{42}$ Microglia and CNS macrophages are capable of acting as antigen-presenting cells for reactive $\mathrm{T}$ cells by expressing MHC class II molecules and stimulatory ligands. These cells cause direct demyelination or axon damage by production of reactive oxygen species, TNFs, $\gamma$-IFN, and nitric oxide. ${ }^{43}$ Dual roles for microglia cells and macrophages have been proposed including destructive processes when acting as antigen-presenting cells and having an important function during neuronal recovery by scavenging damaged myelin following inflammatory attacks. ${ }^{44}$

Normal nerve conduction is critically dependent on proper functioning of sodium, potassium, and calcium ion channels. Animal and human data suggest alterations in distribution and function of sodium channels, particularly sodium subchannel type $\mathrm{Na}_{\mathrm{v}} 1.6$, are present in damaged axons. ${ }^{45}$ Persistent sodium channel dysfunction leads to excessive intracellular calcium concentrations due to maladaptive $\mathrm{Na}^{++} / \mathrm{Ca}^{++}$ion exchange. Cellular death and axonal degeneration consistent with chronic MS have been attributed to ion channel aberrations. ${ }^{46}$ Cellular calcium levels are also regulated, in part, via glutamate-gated receptors. Activation of glutamate receptor 5 can facilitate influx of extracellular calcium and release of additional calcium from intracellular stores. ${ }^{47}$

Estrogen supplementation in EAE animal models suggests estrogens alter the immune response of MS. In vitro testing documents a phenotypic shift from Th1 to Th2 expression during estrogen use in EAE models. ${ }^{48}$ The Th2dominant expression results from altered cytokine production, increased IL-10 levels, ${ }^{49}$ and increased IgG1 antibody production specific for the autoantigen, MBP. ${ }^{50}$ Additional studies in estrogen receptor knockout mice have shown that protective effects of estradiol and estriol are dependent on estrogen receptor $\alpha$ ligands. Estrogen receptor $\beta$ ligands may act in concert with or oppose the actions of estrogen receptor $\alpha .^{51}$ Estrogen receptors are expressed by dendritic ${ }^{52}$ and microglial cells. ${ }^{53}$ Excellent reviews specific to estrogens effects in EAE and its potential implications for MS therapy are available. ${ }^{54,55}$

\section{Traditional therapy for MS}

Acute MS exacerbations are typically managed with a 3- to 7-day course of IV methylprednisolone, which may be followed by a prednisone taper. Short courses of oral or IV corticosteroids decrease inflammation in nerve tissue and shorten the duration of exacerbation. Short-course glucocorticoid use is generally well tolerated, but adverse effects may include gastrointestinal upset, mental status changes, and unmasking of infection. Repeated use of glucocorticoids may increase the risk of fracture. ${ }^{1}$

Historically, chronic treatment for MS was aimed at symptoms management. Current disease-modifying therapies include IFN $\beta$-1a and $1 \mathrm{~b}$, glatiramer acetate, and natalizumab, which prevent relapse and slow disease progression for RRMS but fail to show benefit in progressive forms of MS.

\section{IFN- $\beta$ /glatiramer acetate}

IFN $\beta$ - $1 \mathrm{a}$ and $1 \mathrm{~b}$ and glatiramer acetate were the first widely used disease-modifying agents, believed to primarily work by decreasing the number of $\mathrm{T}$ cells and interfering with T-cell activation. The medications have modest efficacy with decreases in MS relapse rates of $29 \%-37 \%$ and reductions in development of new, gadolinium-enhancing ( $\mathrm{GdE}+$ ) lesions on MRI. ${ }^{56-59}$ However, they do not reverse existing CNS damage and have not significantly altered development of permanent disability. ${ }^{3}$ Although the clinical significance is uncertain, efficacy of these agents may be further compromised by neutralizing antibodies. ${ }^{2,60}$ Excellent reviews of the advantages, adverse effects, and limitations of these therapies are published in clinical practice guidelines from the American Academy of Neurology ${ }^{61}$ and the European Federation of Neurological Societies. ${ }^{62}$

\section{Natalizumab}

Natalizumab was approved in 2004 for treatment of RRMS after demonstrating promising efficacy and safety results in Phase III trials. Natalizumab, a monoclonal antibody against $\alpha-4$ integrin, has a novel mechanism of action of 
blocking leukocyte trafficking across the BBB. Results from the AFFIRM trial demonstrated that natalizumab decreased relapse rates by $68 \%$ at 1 year, reduced sustained disability by $42 \%$ over 2 years, and decreased MRI lesion activity. ${ }^{63}$ Natalizumab therapy is currently only available to patients enrolled in the Tysabri Outreach Unified Commitment to Health (TOUCH ${ }^{\circledR}$ ) prescribing program due to its association with progressive multifocal leukoencephalopathy (PML), a rare, demyelinating neurological disorder caused by the reactivation of the JC virus. The incidence of PML in patients receiving 24-36 months of therapy is estimated to be 1/1000 in the United States and 2/1000 outside the United States. The reason for the increased risk outside of the United States is unknown. As of March 2010, there had been 67,700 natalizumab patients worldwide with 55 confirmed cases of PML as of June 7, 2010. Approximately $20 \%$ of patients with PML have died and the others have varying levels of disability. ${ }^{64}$ There are no reported cases of PML with $<12$ infusions and no experience with natalizumab use beyond 36 months. Unfortunately, there appears to be no way to identify patients at highest risk of acquiring PML, and no prevention or specific treatment options for PML exists. Plasma exchange or immunoadsorption has been used in some patients with confirmed PML to lower circulating natalizumab levels. Many of these patients have experienced immune reconstitution inflammatory syndrome. Based on accumulating data, the FDA has now issued warnings that the risk of PML increases with number of infusions. ${ }^{65}$

\section{Mitoxantrone}

Mitoxantrone is approved for use in RRMS and SPMS but is considered a second-line agent due to cardiomyopathy, leukemia, leucopenia, and infection. Due to concerns of accumulating cardiomyopathy risk, maximum lifetime dose is $140 \mathrm{mg} / \mathrm{m}^{2}, \sim 11$ doses. ${ }^{60}$ Patients need to have an echocardiogram performed at baseline and during and after treatment to monitor for cardiomyopathy. ${ }^{66}$

Effective therapy for slowing the course of PPMS has been and remains discouraging. Trials with IFN $\beta$ - $1 \mathrm{a}$ and $1 \mathrm{~b}$ and glatiramer have not demonstrated significant benefit. Preliminary data from single, small studies of mitoxantrone, cladribine, or methotrexate in PPMS patients have demonstrated little to no benefit. Comprehensive data from these trials are not available, and no medication has been conclusively proven to improve PPMS. ${ }^{67}$ Stem cell therapy has shown some benefit, but this therapy is still investigational and controversial.

\section{New agents: major Phase III trials Fingolimod}

Fingolimod (FTY720) is a S1P1 receptor modulator. S1P1 receptors on lymphocytes respond to various stimuli that signal them to egress from lymph tissue. During animal experiments, fingolimod use prevented the formation of EAE, following exposure to myelin antigens and ameliorated chronic neurologic deficits. ${ }^{68}$ Phase II human trials of fingolimod demonstrated reductions in annualized MS relapse rate and GdE+ lesion burden. Patients in a Phase II trial experienced bradycardia, elevated liver function tests, and macular edema, but large numbers of patients completed the study and many 'placebo' patients subsequently enrolled in the Phase II extension. ${ }^{69}$

Results from two Phase III trials using fingolimod have recently been published (Table 1). The TRANSFORMS Phase III study (ClinicalTrials.gov number NTC00340834) was a 12-month, double-blind, double-dummy study utilizing regimens of fingolimod 0.5 or $1.25 \mathrm{mg}$ orally/day, compared to weekly injections of $30 \mu \mathrm{g}$ intramuscular IFN $\beta$-1a in 1292 RRMS patients. Enrolled patients receiving either dose of fingolimod experienced reductions in annualized relapse rates, fewer multiple relapses, and longer overall time to first relapse in comparison to the active control group and had a higher percentage of relapse-free patients. Adverse events were experienced by $90 \%$ of all participants; however, 87\%-90\% of the adverse events were judged to be of mild or moderate severity. Bradycardia (2\%-10\%) and first- and second-degree atrioventricular block $(0.2 \%-0.7 \%)$ were more frequent in the fingolimod groups, commonly after the first dose. Neoplasms $(0.5 \%-0.7 \%)$, lymphocytopenia $(0.2 \%-1 \%)$, macular edema, and viral infections also occurred more frequently in fingolimod treatment patients. Two deaths occurred in the fingolimod $1.25-\mathrm{mg}$ therapy group, one from disseminated primary varicella zoster infection and the other from herpes simplex encephalitis. ${ }^{70}$

A second 24-month Phase III trial, FREEDOMS - a double-blind, randomized trial, was conducted in 1272 RRMS patients. Similar to previous trials, RRMS patients, ages $18-55$, with EDSS scores $<5.5$ were considered eligible for enrollment. Oral fingolimod at 0.5 or $1.25 \mathrm{mg}$ daily doses were compared to placebo. Both fingolimod treatment regimens produced similar reductions in the primary study endpoint annualized relapse rate and the principal secondary outcome measure time to disease progression. Fingolimod administration in this trial also postponed progression in EDSS scores and changes in MSFC $\mathrm{z}$ scores and reduced the number of new or enlarging $\mathrm{T}_{2}$-weighted lesions and 


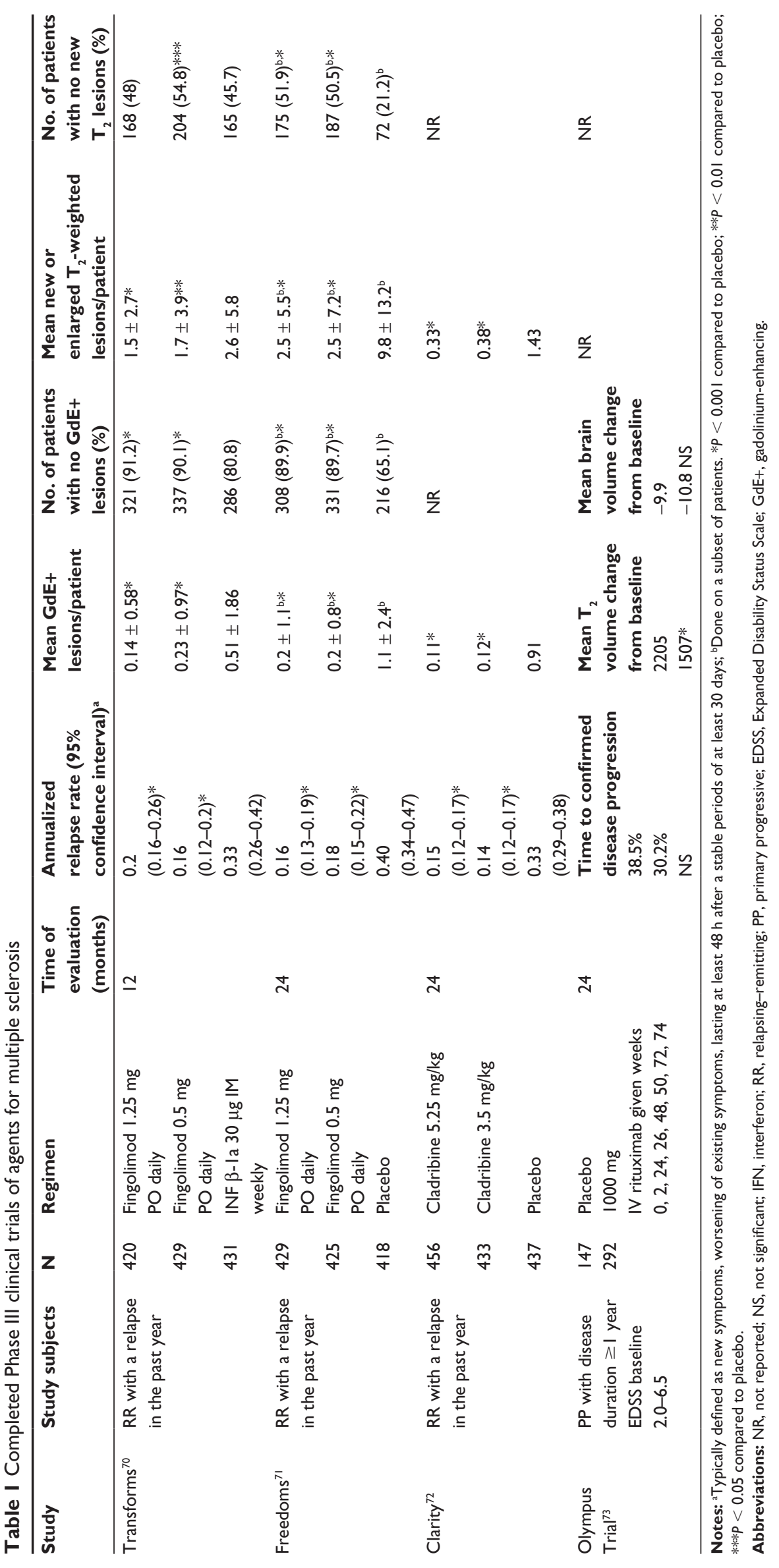


changes in brain volume. Infections, cardiovascular and ocular events, neoplasms, and laboratory abnormalities including reductions in peripheral lymphocyte counts and elevated liver function tests were similar to previous reports. ${ }^{71}$ Nearly $90 \%$ of all individuals in the Phase III trials completed the study, indicating a high acceptance rate for fingolimod.

\section{Cladribine}

Cladribine inhibits DNA synthesis by generation of 2-chlorodeoxyadenosine triphosphate. Cladribine and its metabolites cause reductions in $\mathrm{CD}^{+}$and $\mathrm{CD} 8^{+}$cells, cytokines, chemokines, and cellular migration. Results from the CLARITY, Phase III, trial have recently been published. This trial enrolled more than 1300 RRMS patients in a $1: 1: 1$ assignment ratio of oral cladribine $3.5 \mathrm{mg} / \mathrm{kg}, 5 \mathrm{mg} / \mathrm{kg}$, or placebo in short-course regimens over a 96-week period. During the first 48 weeks of treatment, courses of oral cladribine or placebo were given for the first 4-5 days of a 28-day period. In the $3.5 \mathrm{mg} / \mathrm{kg}$ group, two courses of cladribine were followed by two courses of placebo, starting on day 1 and followed at weeks 5, 9, and 13. For enrollees in the remaining two groups, cladribine $5 \mathrm{mg} / \mathrm{kg}$ or placebo was given for four courses, starting on day 1 and followed at weeks 5, 9, and 13. During the second 48-week treatment block, placebo and both cladribine-assigned patients received two courses of their assigned medications, starting weeks 48 and 52, 8-10 days total treatment. Subcutaneous injections of IFN $\beta$-1a $44 \mu \mathrm{g}$ three times weekly as rescue therapy was allowed after 24 weeks if patients had sustained disability or more than a single relapse.

Patients in either cladribine group had significantly fewer relapses, and significantly higher percentages remained 'relapse-free' in comparison to those assigned placebo. Reductions in need for rescue medication and prolonged time to first relapse also occurred in cladribine groups. Lymphocytopenia, neutropenia, and thrombocytopenia were more common in patients receiving cladribine. Cladribinetreated patients experienced more mild or moderate infections including herpes zoster infections, and one death occurred due to reactivation of tuberculosis. ${ }^{72}$

\section{Rituximab}

PPMS patients receiving rituximab during the OLYMPUS trial, the only Phase III trial, did not experience significant benefit in time to confirmed disease progression over the 96-week study period. However, rituximab patients did demonstrate significant benefit with less mean $\mathrm{T}_{2}$ volume change from baseline compared to placebo. Subgroup analysis from the OLYMPUS trial suggests that confirmed disease progression was delayed in rituximab-treated patients $<51$ years old and those with GdE+ lesions (see Figure 4). ${ }^{73}$

\section{Major Phase II trials Laquinimod}

Laquinimod is another novel oral agent that causes an immune response shift from Th1 to Th2. Roquinimex (linomide), which is structurally similar to laquinimod, was found to cause pericarditis, myocardial infarction, and serositis during Phase III trials, so further research was suspended. Results from a 24-week laquinimod Phase II trial enrolling 306 patients, 18-50 years old, with RRMS have recently been reported (Table 2$).{ }^{75}$ Laquinimod doses of 0.6 or $0.3 \mathrm{mg}$ daily were compared to placebo. Reduction in the number of GdE+ lesions on MRI was the primary endpoint, and secondary endpoints included the cumulative number of GdE+ and $\mathrm{T}_{2}$-weighted lesions and number of clinical relapses.

At the end of the 24-week study period, the adjusted mean cumulative number of GdE+ lesions per scan, $\mathrm{T}_{2}$-weighted lesions, and cumulative number of new $\mathrm{T}_{1}$-hypointense lesions from the last four assessment points were all significantly fewer in the laquinimod $0.6 \mathrm{mg} /$ day treatment group, compared to placebo. No significant change in EDSS scores was observed, but the relatively short study period may have influenced this finding. In contrast, the $0.3 \mathrm{mg} /$ day laquinimod dose did not demonstrate significant benefits in the primary or secondary study endpoints. The overall incidence of adverse events, experienced by $77 \%-84.7 \%$ of all participants, was similar across all groups. Serious adverse events for individuals on laquinimod during this trial consisted of severe menometrorrhagia with myofibroma, elevation of liver enzymes without concomitant jaundice, and exacerbation of pre-existing glaucoma.

\section{Alemtuzumab}

Alemtuzumab (Campath-1 $\mathrm{H}^{\circledR}$ ) $\left(\right.$ Campath $^{\circledR}$; Genzyme Corporation, Cambridge, MA, USA) is a humanized monoclonal antibody that targets CD52, a highly expressed protein on monocytes and lymphocytes. Early human studies of alemtuzumab given in a pulsed regimen led to significant and persistent T-cell reductions and shifted the lymphocyte profile. ${ }^{77}$ A 36-month randomized, blinded Phase II trial of alemtuzumab versus IFN $\beta$-1a in therapy naive, early RRMS patients was recently completed. Patients with EDSS scores of 3 or less and with onset of symptoms within the 


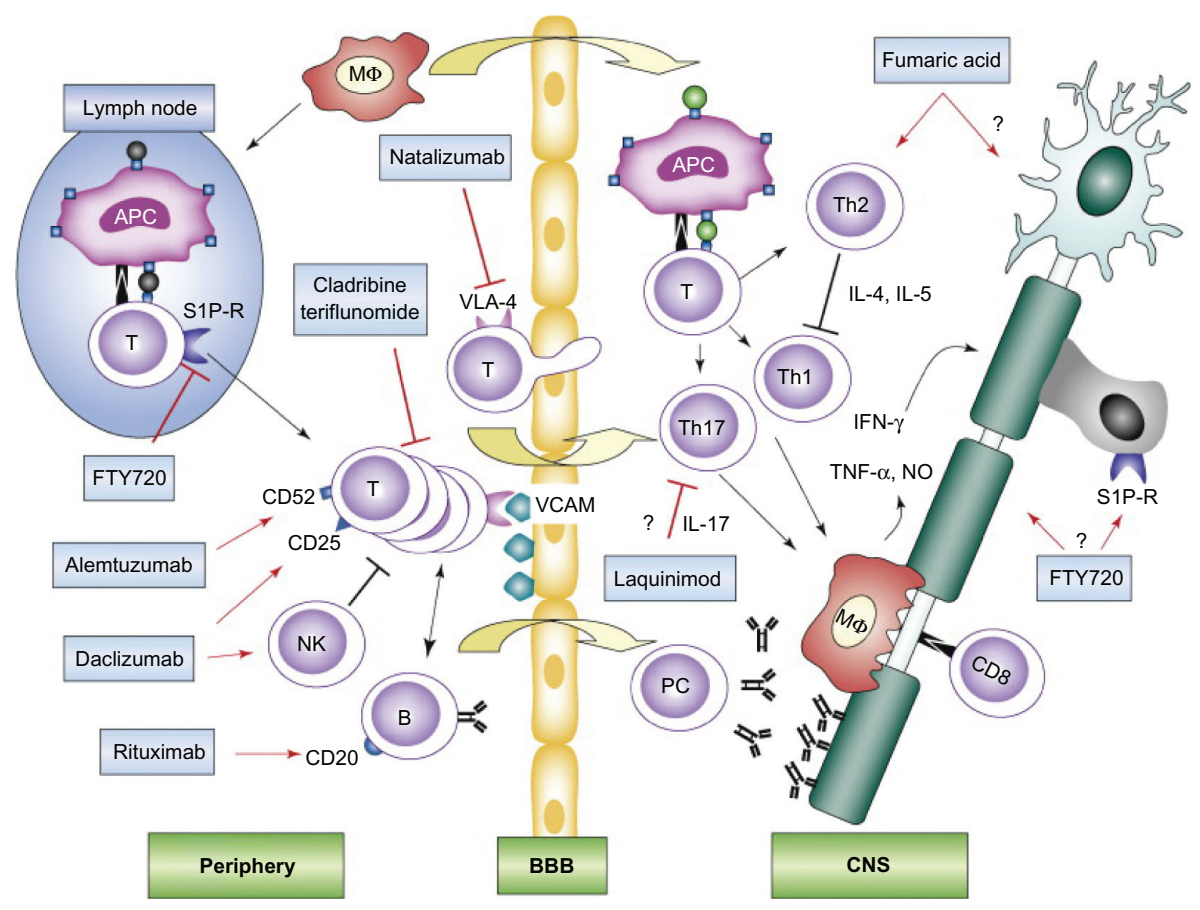

Figure $4 \mathrm{New}$ MS drug mechanisms of action. Schematic depiction of putative targets for the new MS treatment modalities. In lymphoid organs in the periphery, autoreactive T cells interact with APC and B cells and, after activation, are able to cross the BBB. In the CNS, reactivation of autoreactive T cells results in production of effector cytokines such as IFN- $\gamma$, TNF- $\alpha$, and IL-17, attraction of macrophages and microglia, antibody production by plasma cells, and attack by CD $8^{+}$T cells. In concert, these mechanisms lead to demyelination and axonal injury. Interactions of immune cells are shown with black arrows and transmigration over the BBB is displayed with yellow arrows. Red arrows indicate therapeutic interactions with pointed arrows standing for targeting of specific cell types or molecules, T-shaped lines in red indicate blocking of pathways or receptors. Hypothetic mechanisms not proven in vivo are depicted with a question mark.

Copyright (c) 2008, Elsevier. Adapted with permission from Linker RA, Kieseier BC, Gold R. Identification and development of new therapeutics for multiple sclerosis. Trends Pharmacol Sci. 2008;29(1 I):558-565. ${ }^{129}$

Abbreviations: APC, antigen-presenting cell; B, B cell; BBB, blood-brain barrier; CNS, central nervous system; IL, interleukin; INF- $\gamma$, interferon- $\gamma$; NK, natural killer cell; NO, nitric oxide; PC, plasma cell; SIP-R, sphingosine-I-phosphate receptor; Th, T-helper cell; TNF- $\alpha$, tumour necrosis factor- $\alpha$; VCAM, vascular cell adhesion molecule-I.

previous 36 months at time of screening were allocated to alemtuzumab 12 or $24 \mathrm{mg} /$ day or IFN $\beta$-1a $44 \mu \mathrm{g}$ given subcutaneously three times per week. Alemtuzumab administration regimens consisted of 5-consecutive-day cycles of intravenous infusions during the first month followed by three consecutive daily intravenous infusions given at months 12 and 24. Primary outcome measures were frequency of relapse rates and time to sustained accumulated disability. Secondary outcome measures included changes in $\mathrm{T}_{2}$-weighted MRI findings, brain volume, and proportion of patients without relapse.

Patients receiving either dose of alemtuzumab demonstrated significantly less sustained accumulated disability at 6 months and fewer relapses than did patients receiving IFN $\beta$-1a. Both alemtuzumab dosing regimens produced significant benefits with respect to comparator for early MRI lesion changes and brain volume. The safety profile of alemtuzumab was markedly different from IFN $\beta$-1a, with alemtuzumab-administered patients more likely to experience elevations in liver function tests, upper and lower respiratory tract infections, hyper or hypothyroidism, stomatitis, and rash. Five of six cases of immune thrombocytopenic purpura occurred in the alemtuzumab groups, causing the death of one patient, and ultimately leading to suspension of the trial. ${ }^{77}$

\section{Daclizumab}

Daclizumab is a monoclonal anti-CD25 antibody that stimulates the production and enhances the function of CD56 $6^{\text {bright }}$ natural killer cells. A recent study was conducted to determine whether combination daclizumab and IFN $\beta$-1a or $1 b$ therapy would produce favorable additive effects on relapse rate, lesion development, and progression. Additional outcome measures included investigation of new biomarkers and exploration of different dosing regimens. ${ }^{79}$ Fifteen MS patients who had experienced more than one exacerbation or had increasing disability within the previous year and at least two contrast-enhancing lesions on MRI were enrolled. Intravenous infusions of daclizumab doses of $1 \mathrm{mg} / \mathrm{kg}$ were given at 2-week intervals for the first two doses followed thereafter by infusions every 4 weeks. If MRI determined that contrast-enhancing lesions were reduced by $75 \%$ over 


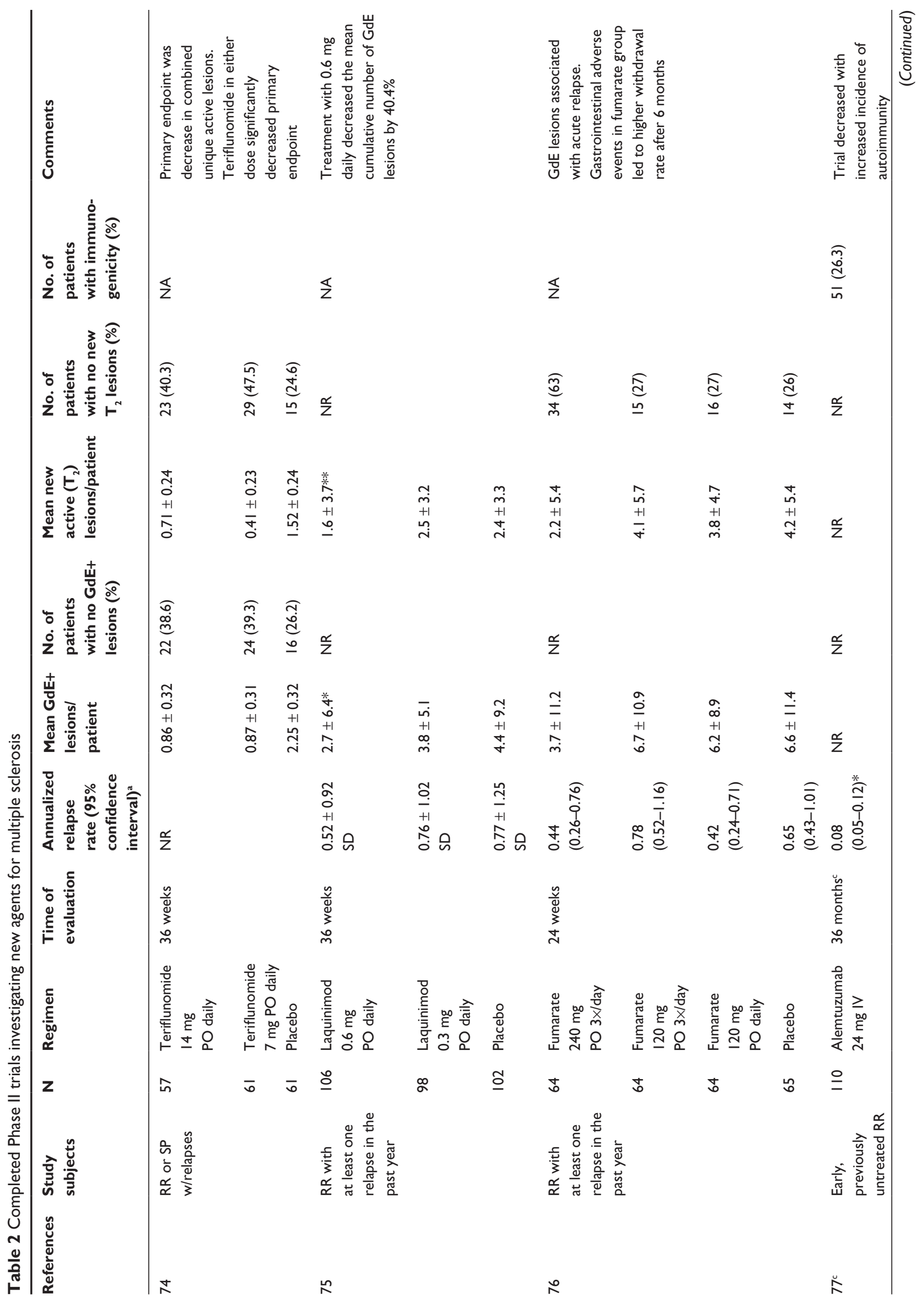




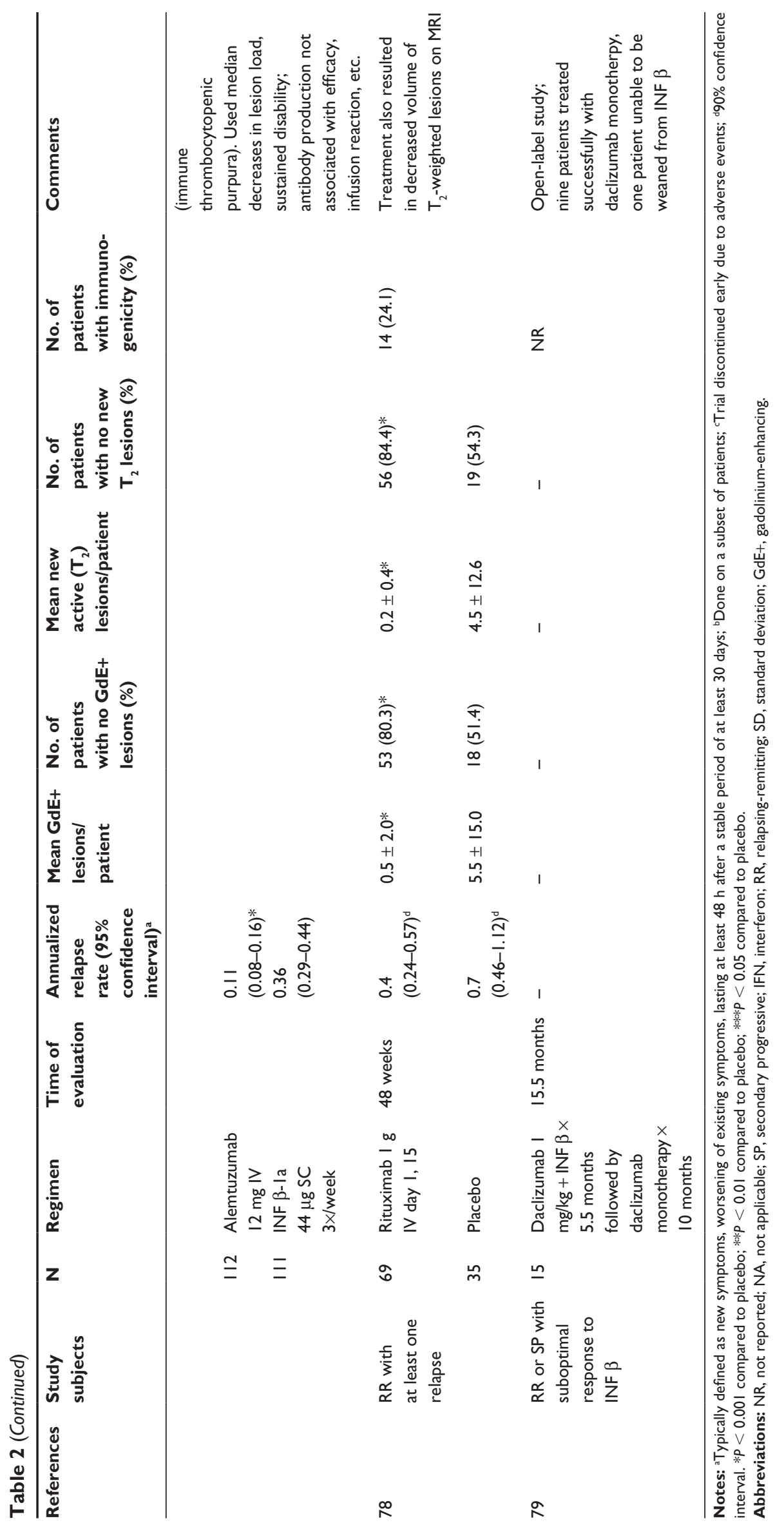


baseline at the 5.5-month assessment, $\beta$-IFN was tapered over 2-4 weeks, discontinued, and daclizumab monotherapy was continued for 10 months. If patients did not reach a $75 \%$ reduction in contrast-enhanced lesions at the 5.5 month assessment, the dose of daclizumab was doubled. IFN $\beta-1 \mathrm{a}$ or $1 \mathrm{~b}$ therapy was reinstated if a patient's monthly MRI revealed sustained lesion progression in any 2-month period. The number of $\mathrm{T}_{2}$-weighted lesions, brain fractional volume, volume of $\mathrm{T}_{1}$-weighted lesion hypointensities, and changes in EDSS, Scripps Neurological Rating Scale, and MSFC scores were secondary outcome measures. Blood samples were analyzed to quantify the number and percentage changes in $\mathrm{CD}^{+} / \mathrm{CD}^{+}, \mathrm{CD}^{+} / \mathrm{CD}^{+} \mathrm{T}$ cells, and $\mathrm{CD} 56^{\text {bright}} /$ $\mathrm{CD}^{-}$and $\mathrm{CD}^{-\mathrm{dim}} / \mathrm{CD}^{-}$natural killer cells. IFN $\beta$ was discontinued in 14 patients but was reinstated later in three patients.

Overall, new contrast-enhancing lesions were reduced by $72 \%$, and improvements were reported for all of the clinical assessments. Seven patients were characterized as partial responders and seven fulfilled criteria as full responders based upon percentage decrease in $\mathrm{CD}^{+} / \mathrm{CD} 4^{+}$cells. Two patients developed systemic immune response reactions and did not complete the trial. Lymphopenia and generalized lymphadenopathy occurred in two other patients requiring interruption of daclizumab therapy but not withdrawal from the trial. ${ }^{79}$

\section{Rituximab}

Rituximab is a chimeric monocolonal antibody targeting $\mathrm{CD} 20^{+}$B lymphocytes, which has been used for B-cell lymphomas as adjuvant chemotherapy. Although T-cell infiltration and response have long been linked to disease activity in MS, autoimmune B cells and the corresponding humoral response also play a role in disease progression.

Rituximab was studied in a Phase II, double-blind, placebo-controlled trial enrolling 104 patients with RRMS. ${ }^{78}$ During the 48-week study, patients were stratified in a $2: 1$ fashion to receive rituximab $1000 \mathrm{mg}$ intravenously or placebo on weeks 1 and 15 and were monitored for disease progression based on relapse rates and lesions detected with MRI. Patients enrolled were 18-55 years old, had at least one relapse in the previous year, and had baseline EDSS scores ranging from 0 to 5.0. Patients were excluded if the relapse occurred in the previous 30 days or if they required recent use of anti-inflammatory therapy or alternative MS treatments. Patients' EDSS scores, MRI imaging changes, peripheral B-cell levels, and adverse events were followed.
Patients treated with rituximab had significantly fewer total and new GdE+ lesions at weeks 12, 16, 20, and 24 of the trial $(P<0.001)$; these results were sustained for 48 weeks $(P<0.001)$. Additionally, the proportion of patients who experienced a relapse was significantly lower in the rituximab group at weeks $24(14.5 \%$ versus $34.3 \%, P=0.02)$ and $48(20.3 \%$ versus $40.0 \%, P=0.04)$. Adverse events were higher in the rituximab group, with infusion-related adverse events within $24 \mathrm{~h}$ being the most common $(78.3 \%$ versus $40.0 \%$ ). Urinary tract and sinus infections were also more common, although no clinically significant opportunistic infections were reported. Within the treatment group, 16 of 65 patients $(24.6 \%)$ tested positive for antichimeric antibodies to rituximab. ${ }^{78}$

\section{Fumarate}

Dimethyl fumarate and its active metabolite, methyl hydrogen fumarate, have been shown to decrease oxidative stress and protect axons from inflammatory mediators. ${ }^{76}$ Fumarate was studied in 257 patients in a double-blind, prospective, randomized, placebo-controlled trial, where patients received oral fumarate $120 \mathrm{mg}$ once daily, 120 or $240 \mathrm{mg}$ three times daily, or placebo. The trial was of 24 weeks' duration followed by a 24-week extension phase. The placebo group during the initial 24-week study was switched to the fumarate $240 \mathrm{mg}$ three times daily dose during the 24-week extension to augment safety analysis.

Study results demonstrated a decrease in the primary endpoint of mean number of GdE+ lesions by $69 \%$ in the $240 \mathrm{mg}$ three times daily treatment group versus placebo from week 12 to 24 (4.5 versus $1.4, P<0.0001$ ). Fumarate $240 \mathrm{mg}$ three times daily reduced new or enlarging $\mathrm{T}_{2}$-hyperintense $(P=0.0006)$ and $\mathrm{T}_{1}$-hypointense $(P=0.014)$ lesions and relapse rates by $32 \%(0.44$ versus 0.65 for placebo; $P=0.272)$ compared to placebo. Adverse events that were higher in all fumarate groups included flushing, abdominal pain, headache, and fatigue. ${ }^{76}$

\section{Teriflunomide}

Teriflunomide, an active metabolite of leflunomide, inhibits dihydro-orotate dehydrogenase, a key enzymatic step required in pyrimidine synthesis. Teriflunomide inhibits T-cell activation by blocking interaction with antigen-presenting cells, inhibiting tyrosine kinase, or other inflammatory mediators. ${ }^{80}$ A 36-week, double-blind, Phase II study enrolling both RRMS and SPMS patients evaluated the effectiveness of teriflunomide 7 or $14 \mathrm{mg}$ daily versus placebo. The number of combined unique MRI lesions per scan was the primary 
study endpoint, whereas relapse rate frequency, accumulation of disability, and MRI-defined disease burden represented the major secondary endpoints.

Significant reductions in combined unique active lesions per scan occurred in both the teriflunomide $7(P<0.03)$ and $14 \mathrm{mg}(P<0.01)$ groups compared to placebo. ${ }^{74}$ The TEMSO trial, 108-week, placebo-controlled Phase III study using active treatment regimens of teriflunomide 7 or $14 \mathrm{mg}$ / day, has completed recruitment but is awaiting completion (www.clinicaltrials.gov).

\section{Estrogen}

Retrospective human cohort studies ${ }^{81}$ and a prospective trial ${ }^{82}$ tracking relapse rates in women with RRMS have found that relapses are less common during the third trimester of pregnancy and more exacerbations occur during the first 3 months postpartum. ${ }^{81,82}$

Although women with more frequent relapses prior to and during pregnancy have a higher likelihood of relapses in the 3-month postpartum period, no pattern exists to predict in advance who is more likely to relapse. After the initial 3-month postpartum period, relapse rates tend to regress to prepregnancy frequencies for the next 21 months without affecting disease progression. ${ }^{82}$

Two studies have been published that evaluated estrogen supplementation in nonpregnant women with MS. Sicotte et $\mathrm{al}^{83}$ enrolled 12 female patients with clinically definite MS; six with RRMS and six with SPMS. Ten patients (six RRMS, four SPMS) finished the 18-month crossover design trial, which consisted of 6 months' treatment with oral estriol ( $8 \mathrm{mg} /$ day) preceded and followed by 'usual' therapy. Major study endpoints included EDSS, PASAT, nine-hole peg test, MRI scans, and response to delayed hypersensitivity testing to tetanus and candida. Serum estriol levels obtained during the treatment phase of the study indicated estriol levels were comparable to women who were 6 months pregnant.

$\mathrm{GdE}+$ lesion volume and number were reduced in all 10 patients at the end of the treatment phase when compared to pretreatment baselines; reductions were primarily driven by the changes in the six RRMS patients. Lesion numbers and size returned to near pretreatment levels after the 6-month post-treatment block.

During a subsequent 4-month retreatment extension phase, MRI lesion volumes and numbers again significantly decreased. PASAT scores among RRMS patients improved, but no other clinical measures improved or reached statistical significance for either RRMS or SPMS patients. Reduction in delayed hypersensitivity reaction to tetanus and candida, which are surrogate markers for Th2 immunity shifting, was evident during the treatment phase. Estriol supplementation was generally well tolerated with menstrual cycle abnormalities being the most frequently associated symptom. During the 4-month retreatment extension phase, all but one patient also received progesterone $100 \mathrm{mg} /$ day. ${ }^{83}$

A second estriol trial enrolled 10 female patients (six RRMS and four SPMS) in a crossover design trial in similar 6-month blocks to determine the mechanisms responsible for the Th2 shift observed in the earlier study. MRI scans were obtained monthly, and blood was obtained every 3 months. Immune cell and cytokine population analysis was conducted to elucidate estriol effects.

Decreases in $\mathrm{CD}^{+}$and $\mathrm{CD}^{+} \mathrm{T}$ cells, increases in $\mathrm{CD} 19^{+} \mathrm{B}$ cells, and no change in $\mathrm{CD} 64^{+}$monocytes/macrophages were noted during the estriol treatment phase with a greater effect experienced by the RRMS patients. Increased intracellular IL-5 and IL-10 and decreased intracellular TNF- $\alpha$ occurred during estriol treatment. Reductions of cells to pretreatment levels occurred during the post-treatment phase. ${ }^{84}$

\section{Stem cell transplantation}

Hematopoietic stem cell transplantation (HSCT) potential for modulating or reversing defective immunological responses of MS is perhaps the most hopeful of all emerging therapies, at least in theory. The premise is that unaffected stem cells can be used to 'reset' or restore self-tolerant cellular populations of the immune system after the dysfunctional cells have been eliminated via irradiation or chemotherapy.

The origin of the stem cells is either autologous (from the same individual) or allogenic (cells from another individual without the disease in question). Nonmyeloablative therapy is commonly employed for autologous HSCT which does not completely obliterate marrow cells but significantly reduces the number of cells. The patient's remaining stem cells are capable of self-regeneration, although sometimes after chemotherapy, autologous stem cells are supplemented to lessen the patient's duration of marrow suppression. In allogenic HSCT, myeloablative chemotherapy is used to completely destroy the patient's marrow, thus theoretically eliminating the defective cells entirely. The intensity of myeloablative response is determined by the specific agent chosen, whether combinations of ablative agents are used, and if chemotherapy is supplemented with irradiation. When allogenic cells are used for replacement, 'host-versus-graft' reactions post stem cell transfer are possible. 
Autologous HSCT is not generally considered a 'cure' because small numbers of 'defective' cells may re-emerge. Some argue that autologous HSCT is more appropriate for individuals with nonlife-threatening autoimmune diseases because of mortality risk associated with allogenic $\mathrm{HSCT}^{85}$ Allogenic HSCT is typically reserved for patients with severe or rapidly progressive disease since the risks associated with this procedure are more substantial than autologous HSCT.

After successful 'proof of concept' testing in EAE animal models, HCST underwent human Phase I and Phase II trials, mostly in refractory MS patients. ${ }^{86}$ Early MS trials typically enrolled PPMS or SPMS patients and used highintensity myeloablative regimens, which often also included irradiation or busulfan. These trials generally arrested disease progression in $30 \%-70 \%$ of patients, depending upon baseline EDSS scores and duration of post-treatment followup. ${ }^{87,88}$ These favorable findings were offset by substantial mortality $(4 \%-40 \%)$ and an engraftment syndrome characterized by rash and noninfectious fever in up to $50 \%$ of patients. ${ }^{87-89}$

Table 3 Ongoing Phase III trials

\begin{tabular}{|c|c|c|c|c|c|}
\hline $\begin{array}{l}\text { Experimental } \\
\text { agent }\end{array}$ & Intervention & Description & Trial identifier $^{a}$ & $\begin{array}{l}\text { Status/ } \\
\text { completion date }\end{array}$ & $\begin{array}{l}\text { Anticipated } \\
\text { no. of patients }\end{array}$ \\
\hline \multirow[t]{5}{*}{ Teriflunomide } & $\begin{array}{l}\text { Teriflunomide } 7 \text { or } \\
14 \mathrm{mg} \text { versus placebo }\end{array}$ & $\begin{array}{l}\text { Determine the effect of } \\
\text { teriflunomide on } \\
\text { conversion of CIS to } \\
\text { clinically definite MS }\end{array}$ & $\begin{array}{l}\text { NCT00622700 } \\
\text { TOPIC }\end{array}$ & $\begin{array}{l}\text { Recruiting/ } \\
\text { April } 2015\end{array}$ & 780 \\
\hline & $\begin{array}{l}\text { Teriflunomide } 7 \text { or } \\
\text { I } 4 \mathrm{mg} \text { versus INF } \beta \text { - Ia }\end{array}$ & $\begin{array}{l}\text { Effectiveness of } \\
\text { teriflunomide versus } \\
\text { INF } \beta \text { - Ia in RRMS }\end{array}$ & $\begin{array}{l}\text { NCT00883337 } \\
\text { TENERE }\end{array}$ & $\begin{array}{l}\text { Recruiting/ } \\
\text { October 201 I }\end{array}$ & 300 \\
\hline & $\begin{array}{l}\text { Teriflunomide versus } \\
\text { placebo }\end{array}$ & $\begin{array}{l}\text { Effectiveness and safety of } \\
\text { teriflunomide versus } \\
\text { placebo for RRMS }\end{array}$ & $\begin{array}{l}\text { NCT00I34563 } \\
\text { TEMSO }\end{array}$ & $\begin{array}{l}\text { Ongoing/ } \\
\text { July } 2010\end{array}$ & 1080 \\
\hline & $\begin{array}{l}\text { Teriflunomide } 7 \text { or } \\
14 \mathrm{mg} \text { versus placebo }\end{array}$ & $\begin{array}{l}\text { Effect of teriflunomide } \\
\text { versus placebo for RRMS }\end{array}$ & $\begin{array}{l}\text { NCT0075I88I } \\
\text { TOWER }\end{array}$ & $\begin{array}{l}\text { Recruiting/ } \\
\text { September 20II }\end{array}$ & 1110 \\
\hline & $\begin{array}{l}\text { Teriflunomide } 7 \text { or } \\
14 \mathrm{mg}\end{array}$ & Safety extension study & NCT00803049 & $\begin{array}{l}\text { Ongoing/ } \\
\text { October } 2010\end{array}$ & 1080 \\
\hline \multirow[t]{2}{*}{ Laquinimod } & $\begin{array}{l}\text { Laquinimod } 0.6 \mathrm{mg} \\
\text { PO daily versus } \\
\text { placebo }\end{array}$ & $\begin{array}{l}\text { Safety and efficacy of } \\
\text { laquinimod versus placebo } \\
\text { in RRMS }\end{array}$ & $\begin{array}{l}\text { NCT00509|45 } \\
\text { ALLEGRO }\end{array}$ & $\begin{array}{l}\text { Ongoing/ } \\
\text { December } 2010\end{array}$ & 1000 \\
\hline & $\begin{array}{l}\text { Laquinimod } 0.6 \mathrm{mg} \\
\text { PO daily versus placebo, } \\
\text { with INF } \beta \text { - Ia as active } \\
\text { comparator }\end{array}$ & $\begin{array}{l}\text { Efficacy, safety, and } \\
\text { tolerability of laquinimod } \\
\text { versus placebo for RRMS }\end{array}$ & $\begin{array}{l}\text { NCT006052I5 } \\
\text { BRAVO }\end{array}$ & $\begin{array}{l}\text { Ongoing/ } \\
\text { June 20II }\end{array}$ & 1200 \\
\hline \multirow[t]{2}{*}{ Fumarate } & $\begin{array}{l}\text { Fumarate } 240 \mathrm{mg} \text { BID, } \\
250 \mathrm{mg} \text { TID, } \\
\text { versus placebo }\end{array}$ & $\begin{array}{l}\text { Efficacy and safety of } \\
\text { fumarate in RRMS }\end{array}$ & $\begin{array}{l}\text { NCT004202I } 2 \\
\text { DEFINE }\end{array}$ & $\begin{array}{l}\text { Ongoing/ } \\
\text { December } 2010\end{array}$ & 1011 \\
\hline & $\begin{array}{l}\text { Fumarate } 240 \text { mg BID } \\
\text { or TID versus placebo } \\
\text { with GA as an active } \\
\text { comparator }\end{array}$ & $\begin{array}{l}\text { Safety and efficacy of } \\
\text { fumarate in RRMS }\end{array}$ & $\begin{array}{l}\text { NCT0045I } 45 \text { I } \\
\text { CONFIRM }\end{array}$ & $\begin{array}{l}\text { Ongoing/ } \\
\text { April 201I }\end{array}$ & 1232 \\
\hline \multirow[t]{2}{*}{ Alemtuzumab } & $\begin{array}{l}\text { Alemtuzumab I } 2 \text { or } \\
24 \mathrm{mg} \text { versus INF } \beta \text { - Ia }\end{array}$ & $\begin{array}{l}\text { Safety and efficacy of } \\
\text { alemtuzumab in RRMS } \\
\text { who relapse while on GA } \\
\text { or INF } \beta\end{array}$ & $\begin{array}{l}\text { NCT00548405 } \\
\text { CARE-MS II }\end{array}$ & $\begin{array}{l}\text { Ongoing/ } \\
\text { September 2011 }\end{array}$ & 840 \\
\hline & $\begin{array}{l}\text { Alemtuzumab } 12 \mathrm{mg} \\
\text { versus GA }\end{array}$ & $\begin{array}{l}\text { Safety and efficacy of } \\
\text { alemtuzumab in RRMS } \\
\text { who have not previously } \\
\text { been treated except with } \\
\text { steroids }\end{array}$ & $\begin{array}{l}\text { NCT00530348 } \\
\text { CARE-MS I }\end{array}$ & $\begin{array}{l}\text { Ongoing/ } \\
\text { May 20II }\end{array}$ & 581 \\
\hline Daclizumab & $\begin{array}{l}\text { Daclizumab high-yield } \\
\text { process I } 50 \text { mg versus } \\
\text { NF } \beta \text { - Ia }\end{array}$ & $\begin{array}{l}\text { Determine superiority of } \\
\text { DAC HYP compared to } \\
\text { INF } \beta \text {-la in RRMS }\end{array}$ & NCT0I06440I & $\begin{array}{l}\text { Not yet open/ } \\
\text { November } 2013\end{array}$ & 1500 \\
\hline
\end{tabular}

Note: Data used to construct table obtained from ClinicalTrials.gov. Accessed June 22, 2010.

Abbreviations: CIS, clinically isolated syndrome; MS, multiple sclerosis; INF, interferon; RRMS, relapsing-remitting multiple sclerosis; GA, glatiramer acetate; DAC HYP, daclizumab high yield process. 
More recent trials have enrolled less severely affected MS patients and have used less intense myeloablative regimens. These trials maintained the impressive benefits associated with HSCT such as increased survival and improved disability status ratings while minimizing but not totally eliminating the risk of mortality. ${ }^{90-94}$ Burt et al have completed an excellent review of HSCT use in nonmalignant diseases. ${ }^{85}$

Due to the successes of these Phase II trials, patients are currently being recruited for ongoing HSCT Phase III trials (Table 3).

Table 4 Steroid-based combination trials

\begin{tabular}{|c|c|c|c|c|c|c|c|}
\hline Study & $\begin{array}{l}\text { Study } \\
\text { subjects }\end{array}$ & $\mathbf{N}$ & Regimen & $\begin{array}{l}\text { Time of } \\
\text { evaluation }\end{array}$ & $\begin{array}{l}\text { Annualized } \\
\text { relapse rate } \\
(95 \% \text { confidence } \\
\text { interval) } \\
\end{array}$ & $\begin{array}{l}\text { Mean } \\
\text { cumulative } \\
\text { number of } \\
\text { new }\left(\mathrm{T}_{2}\right) \text { lesions }\end{array}$ & Comments \\
\hline MECOMBIN & RRMS & 169 & INF $\beta$-Ia $30 \mu \mathrm{g}$ & 3 years & 0.26 & 8.0 & Sustained disability \\
\hline Study ${ }^{96}$ & & 172 & $\begin{array}{l}\text { IM once weekly + } \\
\text { placebo } \\
\text { INF } \beta \text { - Ia } 30 \mu g \\
\text { IM once weekly + } \\
\text { methylprednisolone } \\
500 \text { mg/day PO for } 3 \text { days }\end{array}$ & & $\begin{array}{l}0.15 \\
\text { Relative } \\
\text { reduction: } 42 \% \\
P=0.086 \\
\text { Patients adherent } \\
\text { to regimen to } \\
\text { end of study }\end{array}$ & $\begin{array}{l}5.2 \\
\text { Relative reduction: } 35 \% \\
P=0.007\end{array}$ & $\begin{array}{l}\text { for } 6 \text { months: } \\
44 \\
46 \\
\text { Hazard ratio: } 0.879 \\
(95 \% \mathrm{Cl} 0.566-1.365) \\
P=0.57\end{array}$ \\
\hline NORMIMS 95 & RRMS & $\begin{array}{l}64 \\
66\end{array}$ & $\begin{array}{l}\text { INF } \beta \text { - Ia ( } 44 \mu \mathrm{g} \mathrm{SC.} \\
\text { three times weekly) + } \\
\text { placebo INF } \beta \text { - Ia } \\
(44 \mu \mathrm{g} \text { SC. } \\
\text { three times weekly) + } \\
\text { methylprednisolone } \\
200 \mathrm{mg} 5 \text { consecutive days } \\
\text { every } 4 \text { weeks }\end{array}$ & 96 weeks & $\begin{array}{l}0.59 \\
0.22 \\
\text { Relative } \\
\text { reduction: } 62 \% \\
(95 \% \mathrm{Cl}: 39-7 \mathrm{I}) \\
P<0.000 \mathrm{I}\end{array}$ & $\begin{array}{l}(\mathrm{n}=56) 3.5 \\
(95 \% \mathrm{Cl}: 2.7-4.7) \\
(\mathrm{n}=54) 2.7 \\
(95 \% \mathrm{Cl}: 2.0-3.8) \\
\text { Relative reduction: } 23 \% \\
(95 \% \mathrm{Cl}: \\
0.50-1.19) \\
P=0.24\end{array}$ & $\begin{array}{l}\text { High withdrawal } \\
\text { rate. Significant } \\
\text { reduction in } \\
\text { relapse rate needs } \\
\text { confirmation from } \\
\text { additional studies }\end{array}$ \\
\hline $\mathrm{ACT}^{97}$ & RRMS & $\begin{array}{l}78 \\
83 \\
74 \\
78\end{array}$ & $\begin{array}{l}\text { I INF } \beta \text { - I a } 30 \mu g \\
\text { IM once weekly + } \\
\text { Placebo } \\
\text { INF } \beta \text { - Ia } 30 \mu g \\
\text { IM once weekly + } \\
20 \mathrm{mg} \text { MTX PO weekly } \\
\text { INF } \beta \text { - Ia } 30 \mu g \\
\text { IM once weekly + } \\
\text { I000 mg IVMP/day } \times \\
3 \text { days bimonthly } \\
\text { INF } \beta \text { - Ia } 30 \mu g \text { IM once } \\
\text { weekly }+20 \mathrm{mg} \\
\text { MTX weekly }+ \text { I000 mg } \\
\text { IVMP/day } \times 3 \text { days } \\
\text { bimonthly }\end{array}$ & 52 weeks & $\begin{array}{l}0.53^{\mathrm{a}} \\
0.40^{\mathrm{a}} \\
0.40^{\mathrm{a}} \\
0.28^{\mathrm{a}}\end{array}$ & $\begin{array}{l}\text { I.8 } \\
\text { I.9 } \\
\text { I.5 } \\
0.9 \\
\text { MTX: odds ratio } 0.98 \\
(95 \% \mathrm{Cl}=0.63-1.54) \\
\text { Wald } P \text { value }=0.93 \\
\text { IVMP: odds ratio } 0.74 \\
(95 \% \mathrm{Cl}=0.47-1.15) \\
\text { Wald } P \text { value }=0.18\end{array}$ & $\begin{array}{l}\text { Event rates were } \\
\text { lower in ACT than } \\
\text { other trials reducing } \\
\text { power of study to } \\
\text { detect differences } \\
\text { MRI measures highly } \\
\text { skewed rank-based } \\
\text { statistics chosen for } \\
\text { most endpoints }\end{array}$ \\
\hline ASA $^{98}$ & RRMS & $\begin{array}{l}60 \\
58 \\
63\end{array}$ & $\begin{array}{l}\text { INF } \beta \text { - I a } 30 \mu g \\
\text { IM once weekly + } \\
\text { AZA and steroid } \\
\text { placebos } \\
\text { INF } \beta \text { - I a } 30 \mu g \\
\text { IM once weekly + } \\
\text { AZA } 50 \mathrm{mg} / \text { day } \\
\text { orally + steroid } \\
\text { placebo INF } \beta \text { - Ia } 30 \mu g \\
\text { IM once weekly + } \\
\text { AZA } 50 \mathrm{mg} / \text { day orally + } \\
\text { prednisone I0 mg/day } \\
\text { every other day }\end{array}$ & $\begin{array}{l}\text { Initial } \\
\text { analysis: } \\
2 \text { year }\end{array}$ & $\begin{array}{l}0.73 \\
0.9 I \\
\text { I.05 } \\
\text { 2-year adjusted } \\
\text { annualized } \\
\text { relapse rate } \\
\text { Trend between } \\
\text { group I and } 3 \\
(P=0.60)\end{array}$ & $\begin{array}{l}30.3 \%(P<0.05) \\
24.6 \% \\
14.5 \% \\
\text { Median percent change } \\
\mathrm{T}_{2} \text { lesion volume from } \\
\text { baseline MRI at } 2 \text { years. } \\
\text { No difference observed } \\
\text { at } 5 \text { years }\end{array}$ & $\begin{array}{l}\text { No superiority } \\
\text { of combination } \\
\text { therapy for primary } \\
\text { endpoint-relapse } \\
\text { rate } \\
\text { At } 5 \text { years, } \\
\text { no statistically } \\
\text { significant } \\
\text { differences in } \\
\text { sustained disability } \\
\text { progression }\end{array}$ \\
\hline
\end{tabular}

Notes: aAdjudicated relapses within I-year follow-up, based on all patients; 'bdjusted for baseline relapse rate, EDSS, duration of MS, age, and gender. Abbreviations: RRMS, relapsing remitting multiple sclerosis; INF, interferon; AZA, azathioprine; MTX, methotrexate, IVMP, intravenous methylprednisolone. 


\section{Combination therapy}

While first-line medications such as the $\beta$-IFNs and glatiramer acetate can reduce relapse rates and retard disease progression in some individuals, most patients progress to further disability. The complex immunological cascade in MS involving T and B cells, multiple adhesion ligands, and numerous secondary costimulatory molecules suggests that multiple points of intervention would be plausible. Using medications with differing mechanisms of action might produce additive or synergistic efficacy when used in combination. Moreover, combination therapy for other inflammatory and autoimmune disorders such as rheumatoid arthritis is commonplace. Trials to determine the safety and efficacy of combination therapy for MS patients have become an area of more intensive research.

\section{Steroid-based combination trials}

Combination use of IFN $\beta$-1a with steroids in the NORMIMS ${ }^{95}$ and $\mathrm{MECOMBIN}^{96}$ trials led to reductions in relapse rates but did not affect time to sustained progression (Table 4). ${ }^{96}$ Data generated from the NORMIMS trial may have been influenced by small enrollment numbers and a high dropout rate exceeding $50 \%$. Patients assigned to steroid groups in the NORMIMS and MECOMBIN studies experienced a higher percentage of adverse effects. IFN $\beta$ therapy combined with methotrexate, methotrexate and steroids, low-dose azathioprine, and low-dose azathioprine plus steroids has not resulted in significant reductions of relapse rates. ${ }^{97,98}$

\section{Natalizumab combination trials}

Relapse rate reductions and significantly fewer new or expanding lesions detected by MRI have been documented in trials combining IFN $\beta$-1a IM or glatiramer acetate with natalizumab (Table 5). The combination of natalizumab and glatiramer did not cause significantly more frequent or severe adverse effects. However, the combination group did produce more neutralizing antibodies. It appeared that the presence of persistent antibodies might be related to increased relapse rates or particular infusion reactions. No evidence of PML was reported during the GLANCE trial or its extension phase. ${ }^{99}$ However, the SENTINEL trial in which natalizumab was combined with IFN was halted early due to the detection of PML in two individuals. ${ }^{33}$

Other smaller investigations combining therapies including cyclophosphamide with IFN $\beta^{100}$ or using mitoxantrone with either IFN $\beta^{101}$ or glatiramer acetate ${ }^{102}$ have shown promise. Numerous other Phase II studies using IFN $\beta$ or glatiramer acetate combined with sodium-blocking agents,

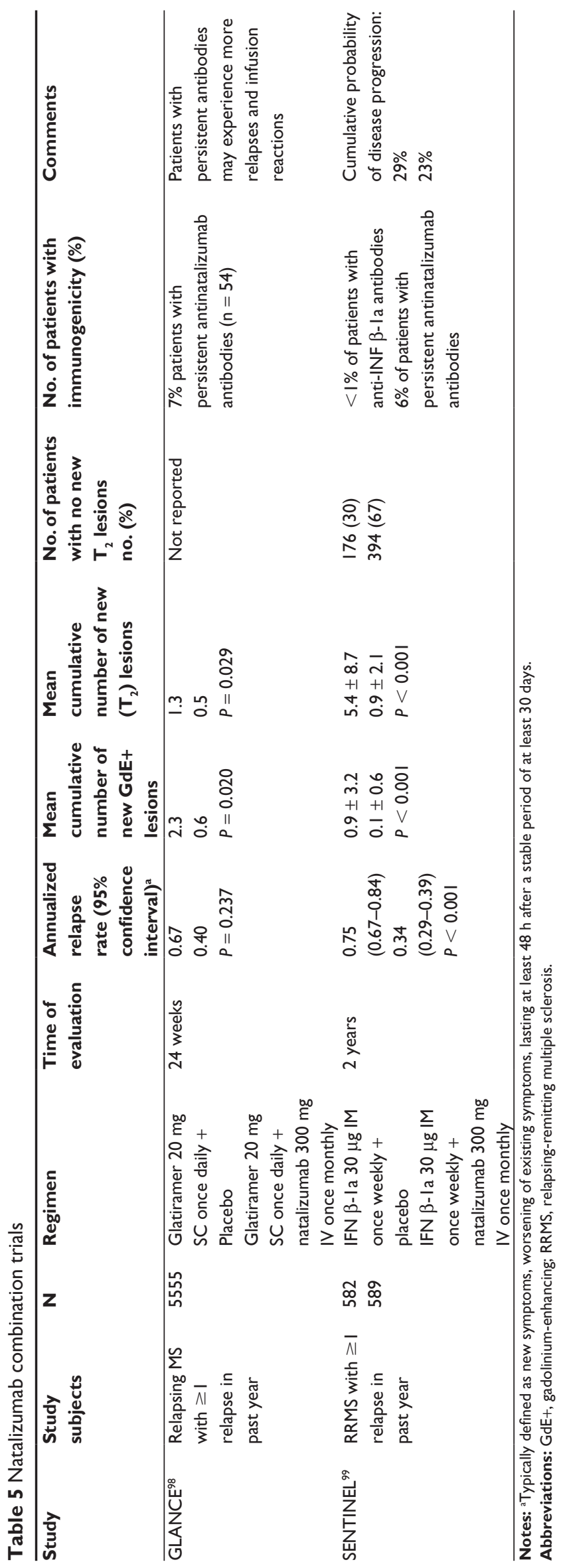


Table 6 Pharmacotherapy of common MS symptoms ${ }^{104-106}$

\begin{tabular}{|c|c|c|}
\hline Symptom & Prevalence estimate (\%) & Pharmacotherapies used \\
\hline Fatigue & $75-90$ & Amantadine, amphetamines, antidepressants, methylphenidate, modafinil, pemoline \\
\hline Weakness/walking difficulties & $65-70$ & Dalfampridine \\
\hline Spasticity & $75-90$ & $\begin{array}{l}\text { Baclofen, botulinum toxin, clonazepam, dantrolene, diazepam, gabapentin, } \\
\text { pregabalin, tizanidine }\end{array}$ \\
\hline Pain/dysesthesias & $50-60$ & Amitriptyline, carbamazepine, gabapentin, lamotrigine, phenytoin, topiramate \\
\hline Bladder dysfunction & $60-75$ & $\begin{array}{l}\text { Amitriptyline, botulinum toxin, darifenacin, desmopressin, dicyclomine, } \\
\text { hyoscyamine, imipramine, oxybutynin, propantheline, prazosin, solifenacine, } \\
\text { tolterodine, trospium }\end{array}$ \\
\hline Depression & $25-50$ & Antidepressants \\
\hline Cognitive deficit & $50-60$ & Amphetamines, donepezil, memantine, rivastigmine \\
\hline Sexual dysfunction & $50-65$ & Alprostadil, sildenafil, tadalafil, vardenafil \\
\hline Tremor/ataxia & $30-60$ & Buspirone, clonazepam, isoniazid, primidone, propranolol \\
\hline
\end{tabular}

statins, antibiotics, or immunostimulants are currently underway. Conway et al have recently published an excellent review. ${ }^{103}$

\section{New developments in treatment of the symptoms of MS}

MS patients suffer from a variety of symptoms which may be treated with pharmacotherapy (Table 6). ${ }^{104}$ Other health interventions including a good diet and exercise may minimize symptoms and help avoid drug therapy. Nondrug interventions such as intermittent self-catheterization for urinary postvoid residual and surgical procedures such as tendon release for spasticity also are utilized. Consultation services such as those in neuropsychology, otolaryngology, and physical therapy are commonly needed to optimize symptom management.

Almost all medications used to manage the symptoms of MS are not specifically indicated for or approved for use in MS patients. Lists of medications used for the given symptoms of MS include both older and newer drugs that share similar mechanisms of action; a discussion of the specific agents is beyond the scope of this article. However, a few developments in the pharmacotherapy of MS symptoms have occurred, most notably dalfampridine (formally called fampridine-SR and 4-aminopyridine), which was recently approved for specific use in MS patients to improve walking. In a large survey, it was found that walking difficulties affect nearly two-thirds of MS patients, with $70 \%$ of those patients reporting it as the most challenging aspect of their disease. Fatigue, which contributes to mobility, also was very common, affecting $76 \%$ of MS patients at least twice weekly. ${ }^{104,105}$

Dalfampridine (Ampyra ${ }^{\mathrm{TM}}$; Acorda Therapeutics, Inc., Hawthorne, NY, USA) is a lipid-soluble drug that readily crosses the BBB and blocks both peripheral and CNS potassium channels. The exposure of potassium channels as a result of myelin destruction in MS allows for disruption of the generation and conduction of action potentials. ${ }^{107}$ Dalfampridine has been found to have a dose-dependent effect to block slowly inactivating or noninactivating voltage-dependent potassium channels. ${ }^{108}$ It has been suggested that this relatively specific mechanism of action could explain why only certain patients respond well to the drug. ${ }^{109}$

The effects of dalfampridine on various measures of clinical efficacy in MS, such as the EDSS, MSFC, ninehole peg test, Timed 25-Foot Walk Test (T25 WT), 12-Item Multiple Sclerosis Walking Scale (MSWS-12), and Lower Extremity Manual Muscle Testing (LEMMT), were evaluated in early studies. From those studies, measures reflective of walking speed (T25 WT and MSWS-12) and lower extremity muscle strength (LEMMT) emerged as outcomes most closely associated with the clinical efficacy of the drug. Investigation of the safety of dalfampridine established the recommended dosage of a sustained-release 10-mg tablet to be taken orally twice daily. In a Phase II study of 206 patients randomized to twice daily dosing with dalfampridine-SR $10,15,20 \mathrm{mg}$, or placebo, serious adverse effects occurred at similar rates in the dalfampridine-SR $10 \mathrm{mg}$ and placebo groups (17\% and 15\%) while higher rates were found in the dalfampridine-SR 15- and 20-mg groups (24\% and 30\%). Seizures occurred in two patients in the $20-\mathrm{mg}$ group, corroborating other data of this serious adverse effect associated with the drug. ${ }^{110,111}$

The approval of dalfampridine was primarily based on two Phase III randomized, double-blind, multicenter clinical trials of patients with all types of MS. Goodman et al randomized 301 patients in a 3:1 ratio to 14 weeks 
of dalfampridine-SR $10 \mathrm{mg}$ twice daily or placebo in the MS-F203 trial; patients were allowed to continue stable doses of MS medications including immunosuppressants. The primary endpoint was the $\mathrm{T} 25 \mathrm{FW}$, with response defined as improvement for at least three of four visits during the treatment period. The MSWS-12 was used to assess patients' evaluations of the clinical meaningfulness of the T25 WT results. Results showed a significantly greater number of patients in the dalfampridine (34.8\%) compared with placebo group (8.3\%) achieved the primary T25 WT outcome $(P<0.0001)$, with a $25.2 \%$ compared to $4.7 \%$ improvement in walking speed in the dalfampridine group. Greater improvement, which was statistically significant $(P=0.0002)$, was seen in the MSWS-12 scores in the T25 WT responders (-6.84) compared to nonresponders (0.05). Overall adverse events occurred with a similar frequency in dalfampridine and placebo groups. Eleven patients $(4.8 \%)$ in the active drug group withdrew due to adverse events, although three patients withdrew during a 2-week placebo run-in period before receiving dalfampridine. Two serious events in the dalfampridine group were believed to be related to treatment, including a seizure judged as possibly related which occurred in a patient who suffered from concurrent sepsis. ${ }^{110}$

The second Phase III trial (MS-F204) included similar MS patients with some degree of walking impairment from 39 centers in the United States and Canada. Patients were randomized 1:1 to dalfampridine-SR $10 \mathrm{mg}$ twice daily or placebo for 8 weeks. The proportion of patients who experienced an improvement in the primary outcome T25 WT and classified as responders was significantly greater in the dalfampridine (42.9\%) compared to placebo (9.3\%) group $(P<0.001)$; response occurred in all types of MS patients. Secondary outcomes also favored dalfampridine responders, with an average increase in mobility over the treatment period (24.7\% compared to $7.7 \%)$ and a significant increase in leg strength compared to the placebo group $(P=0.028)$. Dalfampridine responders also demonstrated improved self-rated MSWS-12 scores compared to nonresponders. Adverse effects in the dalfampridine group affecting more than $10 \%$ of patients included urinary tract infections, falls, and insomnia, but headache, asthenia, dizziness, nausea, back pain, balance disorder, and paresthesia all occurred at least twice as commonly as in the placebo group. Only one patient in the active drug treatment group was discontinued due to a serious adverse effect, which was a patellar fracture judged not to be treatment related. ${ }^{112}$
Follow-up information from the two Phase III trials also has been positive. The dalfampridine responders group in the MS-F204 trial was found to have significant improvement in the physician-reported Ashworth score for spasticity. ${ }^{113}$ Extended efficacy and safety data from 269 patients from the MS-F203 trial enrolled in an open-label study showed that 187 patients $(69.7 \%)$ were still enrolled after an average drug exposure of 2.1 years; the discontinuation rate due to adverse events was $10.8 \%$. Efficacy analysis indicated 66 of 269 patients $(24.9 \%)$ could be classified as Extension Time Walk Responders (ETWRs) after 1 year of treatment; those patients had a mean improvement in walking speed of $>30 \%$ at 1 year and $22 \%$ at 2 years, compared to baseline. Among patients previously defined as T25 WT in the original trial, $42.9 \%$ met criteria for Extension Time Walk Responders. Safety analysis revealed four seizure-related events, giving an incidence of 0.41/100 dalfampridine patient-years, compared to 0.35 previously reported in the general MS population. ${ }^{114}$ Finally, data from open-label analysis of patients from both Phase III trials showed that dalfampridine responders continued to show improvement in walking speed after 2.5 years; a pooled analysis of 631 patients including the Phase III patients plus those from a Phase II study demonstrated that $37.3 \%$ of active drug compared to $8.9 \%$ of placebo recipients were $\mathrm{T} 25 \mathrm{WT}$ responders, with an average improvement in walking speed of $25.3 \%$. Response to dalfampridine was independent of patient factors such as gender, age, baseline EDSS score, MS type, disease duration, and treatment with the various immunomodulator drugs. ${ }^{115}$

Data are lacking to help identify which patients will respond favorably, or poorly, to dalfampridine. Earlier data from a study using dalfampridine-SR $17.5 \mathrm{mg}$ twice daily suggested a correlation between dalfampridine serum concentrations greater than $60 \mathrm{ng} / \mathrm{mL}$ and clinical efficacy. ${ }^{116}$ In contrast, mean plasma dalfampridine concentrations of $27.6-29.2 \mathrm{ng} / \mathrm{mL}$ with a range of $0-66.8 \mathrm{ng} / \mathrm{mL}$ were reported in one of the Phase III trials, suggesting few patients achieved a concentration above $60 \mathrm{ng} / \mathrm{mL}$ at the recommended $10 \mathrm{mg}$ twice daily dosage. ${ }^{110}$ In addition, it is not yet fully delineated what, if any, risk of seizures is associated with dalfampridine at the recommended dosage and what patients may be at increased risk, although the drug is labeled as contraindicated in patients with a history of seizures or/and those with renal impairment. (The drug is $85 \%$ renally eliminated.) ${ }^{109}$ Nerispirdine, another potassium-channel blocker similar to dalfampridine, is currently being studied in Phase II trials. ${ }^{117}$ However, nerispirdine also blocks voltage-dependent sodium 
channels, which may minimize or eliminate any risk of seizure activity. ${ }^{118}$

Other developments in the treatment of MS symptoms concern additional insight to the use of existing agents. Fatigue is the single most common symptom of MS, and modafinil is frequently utilized for this disabling symptom. ${ }^{104}$ A recent double-blind study by Lange et al in a small number of MS patients $(n=21)$ demonstrated that modafinil titrated to $200 \mathrm{mg}$ once daily for 8 weeks provided a sustained improvement in fatigue, as measured by the Fatigue Severity Scale, when compared to placebo. Modafinil resulted in a significant lowering of the mean Fatigue Severity Scale score from a baseline 57.0 to 44 , compared to a change from 52 to 52.5 in the placebo group $(P=0.035) .{ }^{119}$ Results from the study consistently corroborated positive data with modafinil from open-label studies, but contrasted with those from the only previously reported double-blind, placebo-controlled trial which failed to demonstrate benefit from modafinil over a 5-week treatment period. ${ }^{120}$ Stankoff et al had found that modafinil typically titrated to at least $300 \mathrm{mg}$ daily did provide benefit as measured by the Modified Fatigue Severity Scale, but that similar benefit also occurred in the placebo group. ${ }^{121}$ Because the most prolonged study of modafinil in MS patients has only been 12 weeks, there is a need for long-term data regarding the value of this agent.

The symptom of spasticity in MS patients can be useful for movement, but often causes pain, discomfort, or debilitation, which requires pharmacologic intervention. Baclofen and tizanidine are effective oral agents but commonly cause adverse effects of somnolence, weakness, or fatigue. The use of tizanidine at bedtime may provide benefit with less adverse effects compared to daytime use, but multiple daily dosing is often required. ${ }^{106}$ Intrathecal baclofen offers an effective alternative to oral agents, but requires pump implantation and management. Botulinum toxin injectable was approved in 2010 in the United States for treatment of spasticity of the upper limbs, but its value is limited by its focal effect on individual muscles in MS patients, who often have spasticity affecting an entire limb. ${ }^{122}$ Finally, cannabinoids have been investigated for spasticity in MS patients. Most studies have utilized Cannabis sativa extract or the active constituent $\Delta^{9}$-tetrahydrocannabinol given as oral or oromucosal spray preparations and several well-designed blinded placebo-controlled trials have been conducted. Globally, cannabinoids have been found to have consistent subjective, patient-reported benefits on spasticity. However, benefit has typically not been seen in objective outcomes such as
Ashworth scores, and minor adverse effects such as dizziness commonly occur. Serious adverse effects on cognition or psychopathology have not been seen, but studies have been limited to several months, limiting ability to assess long-term effects. ${ }^{123}$

Cognitive impairment has been found to occur in at least $50 \%$ of MS patients; depression can contribute in some patients and is treated with antidepressants. Pharmacotherapy for cognitive dysfunction has primarily centered on neuroactive agents used in the treatment of Alzheimer's disease. ${ }^{104}$ However, studies of cholinesterase inhibitors in MS patients have produced mixed results, prompting recent research of different pharmacologic approaches. ${ }^{124,125}$ Morrow et al reported on the effects of L-amphetamine in $136 \mathrm{MS}$ patients with documented cognitive deficits randomized in a 2:1 ratio to active drug or placebo at 33 centers in the United States. After $\sim 1$ month of therapy, patients receiving L-amphetamine saw no significant benefit in the two primary outcomes of Symbol Digit Modalities Test $(P=0.506)$ or Subject Global Assessment of Change from baseline $(P=0.879)$, but significant benefits with active drug were determined for secondary measures of auditory/visual learning and visual/ special memory. ${ }^{126}$ A recent double-blind, randomized trial by Lovera et al compared 16 weeks of the usual dosage of the NDMA glutamine receptor antagonist memantine to placebo in $114 \mathrm{MS}$ patients with cognitive deficits but without depression. No differences were seen in the primary outcome for changes from baseline for the PASAT and California Verbal Learning Test-II (CVLT-II), Long Delay Free Recall (LDFR), or in several secondary neuropsychiatric measures. ${ }^{127}$

\section{Conclusion}

Agents in Phase III trials that have been shown to reduce relapse rates and decrease the burden of CNS lesions as detected by MRI include fingolimod, alemtuzumab, cladribine, and rituximab. Additionally, several agents such as teriflunomide, daclizumab, laquinimod, and fumarate have reported promising results in Phase II trials. Quality of life concerns for patients with MS are also at the forefront of current research, and advancements in managing spasticity, ambulation, and cognition are also being realized. Despite the promise of new agents and developments in understanding the disease progression and initial inflammatory insult, the long-term risks of new agents remain largely unknown. Research continues to generate novel therapies for modifying MS and aiding in management of common MS symptoms. 


\section{Disclosure}

The authors report no conflicts of interest in this work.

\section{References}

1. Pithadia A, Jain S, Navale A. Pathogenesis and treatment of multiple sclerosis (MS). Int J Neurol. 2009;10(2):1-20.

2. Noseworthy JH, Lucchinetti C, Rodriguez M, Weinshenker BG. Multiple sclerosis. N Engl J Med. 2000;343(13):938-952.

3. Compston A, Coles A. Multiple sclerosis. Lancet. 2002;359(9313): 1221-1231.

4. Polman CH, Reingold SC, Edan G, et al. Diagnostic criteria for multiple sclerosis: 2005 revisions to the "McDonald criteria". Ann Neurol. 2005;58(6):840-846.

5. McDonald WI, Compston A, Edan G, et al. Recommended diagnostic criteria for multiple sclerosis: guidelines from the international panel on the diagnosis of multiple sclerosis. Ann Neurol. 2001; 50(1):121-127.

6. Miller DH, Weinshenker BG, Filippi M, et al. Differential diagnosis of suspected multiple sclerosis: a consensus approach. Mult Scler. 2008;14(9):1157-1174.

7. Frohman EM, Goodin DS, Calabresi PA, et al. The utility of MRI in suspected MS: report of the Therapeutics and Technology Assessment Subcommittee of the American Academy of Neurology. Neurology. 2003;61(5):602-611.

8. Goodin DS, Bates D. Treatment of early multiple sclerosis: the value of treatment initiation after a first clinical episode. Mult Scler. 2009; 15(10):1175-1182.

9. Comi G, Filippi M, Barkhof F, et al. Effect of early interferon treatment on conversion to definite multiple sclerosis: a randomised study. Lancet. 2001;357(9268):1576-1582.

10. Jacobs LD, Beck RW, Simon JH, et al. Intramuscular interferon beta-1a therapy initiated during a first demyelinating event in multiple sclerosis. Champs Study Group. N Engl J Med. 2000;343(13):898-904.

11. Kappos L, Polman CH, Freedman MS, et al. Treatment with interferon beta- $1 \mathrm{~b}$ delays conversion to clinically definite and McDonald MS in patients with clinically isolated syndromes. Neurology. 2006;67(7): $1242-1249$.

12. Comi G, Martinelli V, Rodegher M, et al. Effect of glatiramer acetate on conversion to clinically definite multiple sclerosis in patients with clinically isolated syndrome (PreCISe study): a randomised, double-blind, placebo-controlled trial. Lancet. 2009;374(9700): 1503-1511.

13. Kappos L, Freedman MS, Polman CH, et al. Effect of early versus delayed interferon beta- $1 \mathrm{~b}$ treatment on disability after a first clinical event suggestive of multiple sclerosis: a 3 year follow-up analysis of the BENEFIT study. Lancet. 2007;370(9585):389-397.

14. Kinkel RP, Kollman C, O'Connor P, et al. IM interferon $\beta$-1a delays definite multiple sclerosis 5 years after a first demyelinating event. Neurology. 2006;66(5):678-684.

15. Hauser SL, Oksenberg JR. The neurobiology of multiple sclerosis: genes, inflammation, and neurodegeneration. Neuron. 2006;52(1):61-76.

16. Douglass LH, Jorgensen CL. Pregnancy and multiple sclerosis. Am J Obstet Gynecol. 1948;55(2):332-336.

17. Polman $\mathrm{CH}$, Rudick RA. The multiple sclerosis functional composite: a clinically meaningful measure of disability. Neurology. 2010; 74 Suppl 3: S8-S15.

18. Miller D, Rudick RA, Hutchinson M. Patient-centered outcomes: translating clinical efficacy into benefits on health-related quality of life. Neurology. 2010;74 Suppl 3:S24-S35.

19. Mangano K, Nicoletti A, Patti F, et al. Variable effects of cyclophosphamide in rodent models of experimental allergic encephalomyelitis. Clin Exp Immunol. 2009;159(2):159-168.

20. Bettelli E, Pagany M, Weiner HL, et al. Myelin oligodendrocyte glycoprotein-specific $\mathrm{T}$ cell receptor transgenic mice develop spontaneous autoimmune optic neuritis. J Exp Med. 2003;197(9): 1073-1081.
21. Zamvil S, Nelson P, Trotter J, et al. T-cell clones specific for myelin basic protein induce chronic relapsing paralysis and demyelination. Nature. 1985;317(6035):355-358.

22. Gold R, Linington C, Lassmann H. Understanding the pathogenesis and therapy of multiple sclerosis via animal models: 70 years of merits and culprits in experimental autoimmune encephalomyelitis research. Brain. 2006;129(Pt 8):1953-1971.

23. van der Walt A, Butzkueven H, Kolbe S, et al. Neuroprotection in multiple sclerosis: a therapeutic challenge for the next decade. Pharmacol Ther. 2010;126(1):82-93.

24. Ascherio A, Munger KL. Environmental risk factors for multiple sclerosis. Part I: the role of infection. Ann Neurol. 2007;61(4):288-299.

25. Peltonen L. Old suspects found guilty-the first genome profile of multiple sclerosis. N Engl J Med. 2007;357(9):927-929.

26. The International Multiple Sclerosis Genetics Consortium, Hafler DA, Compston A, et al. Risk alleles for multiple sclerosis identified by a genomewide study. N Engl J Med. 2007;357(9):851-862.

27. Oksenberg JR, Baranzini SE, Sawcer S, Hauser SL. The genetics of multiple sclerosis: SNPs to pathways to pathogenesis. Nat Rev Genet. 2008;9(7):516-526.

28. Steinman L, Martin R, Bernard C, Conlon P, Oksenberg JR. Multiple sclerosis: deeper understanding of its pathogenesis reveals new targets for therapy. Annu Rev Neurosci. 2002;25:491-505.

29. Sospedra M, Martin R. Immunology of multiple sclerosis. Annu Rev Immunol. 2005;23:683-747.

30. Frohman EM, Racke MK, Raine CS. Multiple sclerosis-the plaque and its pathogenesis. $N$ Engl J Med. 2006;354(9):942-955.

31. Stuve O. Knowns and unknowns in the future of multiple sclerosis treatment. J Neurol Sci. 2009;287 Supp1 1:S30-S36.

32. Luster AD, Alon R, von Andrian UH. Immune cell migration in inflammation: present and future therapeutic targets. Nat Immunol. 2005;6(12):1182-1190.

33. Rudick RA, Stuart WH, Calabresi PA, et al. Natalizumab plus interferon beta-1a for relapsing multiple sclerosis. $N$ Engl $J$ Med. 2006;354(9):911-923.

34. Steinman L. A molecular trio in relapse and remission in multiple sclerosis. Nat Rev Immunol. 2009;9(6):440-447.

35. Murugaiyan G, Mittal A, Weiner HL. Increased osteopontin expression in dendritic cells amplifies IL-17 production by $\mathrm{CD} 4^{+} \mathrm{T}$ cells in experimental autoimmune encephalomyelitis and in multiple sclerosis. J Immunol. 2008;181(11):7480-7488.

36. Bettelli E, Oukka M, Kuchroo VK. $\mathrm{T}_{\mathrm{H}}-17$ cells in the circle of immunity and autoimmunity. Nat Immunol. 2007;8(4):345-350.

37. Hur EM, Youssef S, Haws ME, Zhang SY, Sobel RA, Steinman L. Osteopontin-induced relapse and progression of autoimmune brain disease through enhanced survival of activated T cells. Nat Immunol. 2006;8(1):74-83.

38. Chabas D, Baranzini SE, Mitchell D, et al. The influence of the proinflammatory cytokine, osteopontin, on autoimmune demyelination disease. Science. 2001;294(5547):1731-1735.

39. Sinclair C, Mirakhur M, Kirk J, Farrell M, McQuaid S. Up-regulation of osteopontin and $\alpha \beta$-crystallin in the normal-appearing white matter of multiple sclerosis: an immunohistochemical study utilizing tissue microarrays. Neuropathol Appl Neurobiol. 2005;31(3): 292-303.

40. Han MH, Hwang SI, Roy DB, et al. Proteomic analysis of active multiple sclerosis lesions reveals therapeutic targets. Nature. 2008; 451(7182):1076-1081.

41. Ousman SS, Tomooka BH, van Noort JM, et al. Protective and therapeutic role for $\alpha \beta$-crystallin in autoimmune demyelination. Nature. 2007;448(7152):474-479.

42. O'Connor KC, Bar-Or A, Hafler DA. The neuroimmunology of multiple sclerosis: possible roles of $\mathrm{T}$ and $\mathrm{B}$ lymphocytes in immunopathogenesis. J Clin Immunol. 2001;21(2):81-92.

43. Trapp BD, Peterson J, Ransohoff RM, Rudick R, Mork S, Bo L. Axonal transection in the lesions of multiple sclerosis. N Engl J Med. 1998; 338(5):278-285. 
44. Butovsky O, Landa G, Kunis G, et al. Induction and blockage of oligodendrogenesis by differently activated microglia in an animal model of multiple sclerosis. J Clin Invest. 2006;116(4):905-915.

45. Craner MJ, Hains BC, Lo AC, Black JA, Waxman SG. Co-localization of sodium channels $\mathrm{Na}_{\mathrm{v}} 1.6$ and the sodium-calcium exchanger at sites of axonal injury in the spinal cord in EAE. Brain. 2004;127(Pt 2): 294-303.

46. Dutta R, McDonough J, Yin X, et al. Mitochondrial dysfunction as a cause of axonal degeneration in multiple sclerosis patients. Ann Neurol. 2006;59(3):478-489.

47. Ouardouz M, Coderre E, Zamponi GW, et al. Glutamate receptors on myelinated spinal cord axons: II. AMPA and GluR5 receptors. Ann Neurol. 2009;65(2):160-166.

48. Drew PD, Chavis JA, Bhatt R. Sex steroid regulation of microglial cell activation: relevance to multiple sclerosis. Ann N Y Acad Sci. 2003; 1007:329-334.

49. McClain MA, Gatson NN, Powell ND, et al. Pregnancy suppresses experimental autoimmune encephalomyelitis through immunoregulatory cytokine production. J Immunol. 2007;179(12): 8146-8152.

50. Kim S, Liva SM, Dalal MA, Verity MA, Voskuhl RR. Estriol ameliorates autoimmune demyelinating disease: implications for multiple sclerosis. Neurology. 1999;52(6):1230-1238.

51. Morales LB, Loo KK, Liu HB, Peterson C, Tiwari-Woodruff S, Voskuhl RR. Treatment with an estrogen receptor $\alpha$ ligand is neuroprotective in experimental autoimmune encephalomyelitis. J Neurosci. 2006;26(25):6823-6833.

52. Zhu WH, Lu CZ, Huang YM, Link H, Xiao BG. A putative mechanism of remission of multiple sclerosis during pregnancy: estrogen-induced indoleamine 2,3-dioxygenase by dendritic cells. Mult Scler. 2007; 13(1): 33-40.

53. Baker AE, Brautigam VM, Watters JJ. Estrogen modulates microglial inflammatory mediator production via interactions with estrogen receptor $\beta$. Endocrinology. 2004;145(11):5021-5032.

54. Offner H. Neuroimmunoprotective effects of estrogen and derivatives in experimental autoimmune encephalomyelitis: therapeutic implications for multiple sclerosis. J Neurosci Res. 2004;78(5):603-624.

55. Straub RH. The complex role of estrogens in inflammation. Endocr Rev. 2007;28(5):521-574.

56. Interferon beta-1b is effective in relapsing-remitting multiple sclerosis. I. Clinical results of a mutlicenter, randomized, double-blind, placebo-controlled trial. The IFNB Multiple Sclerosis Study Group. Neurology. 1993;43(4):655-661.

57. Jacobs LD, Cookfair DL, Rudick RA, et al. Intramuscular interferon beta-1a for disease progression in relapsing multiple sclerosis. The Multiple Sclerosis Collaborative Research Group. Ann Neurol. 1996; 39(3):285-294.

58. Randomised double-blind placebo-controlled study of interferon $\beta$-1a in relapsing/remitting multiple sclerosis. PRISMS (Prevention of Relapses and Disability by Interferon beta-1a Subcutaneously in Multiple Sclerosis) Study Group. Lancet. 1998;352(9139):1498-1504.

59. Johnson KP, Brooks BR, Cohen JA, et al. Copolymer 1 reduces relapse rate and improves disability in relapsing-remitting multiple sclerosis: results of a phase III multicenter, double-blind, placebo-controlled trial. The Copolymer 1 Multiple Sclerosis Study Group. Neurology. 1995;45(7):1268-1276.

60. Coyle PK. Disease-modifying agents in multiple sclerosis. Ann Indian Acad Neurol. 2009;12(4):273-282.

61. Goodin DS, Frohman EM, Garmany GP Jr, et al. Disease modifying therapies in multiple sclerosis: report of the Therapeutics and Technology Assessment Subcommittee of the American Academy of Neurology and the MS Council for Clinical Practice Guidelines. Neurology. 2002;58(2):169-178.

62. Sorensen PS, Deisenhammer F, Duda P, et al. Guidelines on use of anti-IFN-beta antibody measurements in multiple sclerosis: report of an EFNS Task Force on IFN-beta antibodies in multiple sclerosis. Eur J Neurol. 2005;12(11):817-827.
63. Polman CH, O'Connor PW, Havrdova E, et al. A randomized, placebocontrolled trial of natalizumab for relapsing multiple sclerosis. $N \mathrm{Engl}$ J Med. 2006;354(9):899-910.

64. National Multiple Sclerosis Society. Update on Tysabri and PML: sponsor and FDA provide information on cases and risks. Available from: http://www.nationalmssociety.org/news/news-detail/index. aspx?nid=2308/. Accessed Jun 292010.

65. US. Food and Drug Administration. FDA drug safety communication: risk of progressive multifocal leukoencephalopathy (PML) with the use of Tysabri (natalizumab). Available from: http://www.fda.gov/ Drugs/DrugSafety/PostmarketDrugSafetyInformationforPatientsand Providers/ucm199872.htm/. Accessed Jun 292010.

66. Dangond F. Multiple sclerosis. eMedicine Neurology. 2010. Available from: http://emedicine.medscape.com/article/1146199-print.

67. Miller DH, Leary SM. Primary progressive multiple sclerosis. Lancet Neurol. 2007;6(10):903-912.

68. Fujino M, Funeshima N, Kitazawa Y, et al. Amelioration of experimental autoimmune encephalomyelitis in Lewis rats by FTY720 treatment. J Pharmcol Exp Ther. 2003;305(1):70-77.

69. O’Connor P, Comi G, Montalban X, et al. Oral fingolimod (FTY720) in multiple sclerosis: two-year results of a phase II extension study. Neurology. 2009;72(1):73-79.

70. Cohen JA, Barkhof F, Comi G, et al. Oral fingolimod or intramuscular interferon for relapsing multiple sclerosis. $N$ Engl J Med. 2010; 362(5):402-415.

71. Kappos L, Radue EW, O'Connor P, et al. A placebo-controlled trial of oral fingolimod in relapsing multiple sclerosis. $N$ Engl J Med. 2010; 362(5):387-401.

72. Giovannoni G, Comi G, Cook S, et al. A Placebo-controlled trial of oral cladribine for relapsing multiple sclerosis [phase III]. $N$ Engl J Med. 2010;362(5):416-426.

73. Hawker K, O’Connor P, Freedman MS, et al. Rituximab in patients with primary progressive multiple sclerosis: results of a randomized double-blind placebo-controlled multicenter trial. Ann Neurol. 2009; 66(4):460-471.

74. O'Connor PW, Li D, Freedman MS, et al. A Phase II study of the safety and efficacy of teriflunomide in multiple sclerosis with relapses. Neurology. 2006;66(6):894-900.

75. Comi G, Pulizzi A, Rovaris M, et al. Effect of laquinimod on MRImonitored disease activity in patients with relapsing-remitting multiple sclerosis: a multicentre, randomised, double-blind, placebo-controlled phase IIb study. Lancet. 2008;371(9630):2085-2092.

76. Kappos L, Gold R, Miller DH, et al. Efficacy and safety of oral fumarate in patients with relapsing-remitting multiple sclerosis: a multicentre, randomised, double-blind, placebo-controlled phase IIb study. Lancet. 2008;372(9648):1463-1472.

77. CAMMS223 Trial Investigators, Coles AJ, Compston DA, et al. Alemtuzumab vs interferon beta-1a in early multiple sclerosis. $N$ Engl J Med. 2008;359(17):1786-1801.

78. Hauser SL, Waubant E, Arnold DL, et al. B-cell depletion with rituximab in relapsing-remitting multiple sclerosis. $N$ Engl J Med. 2008; 358(7):676-688.

79. Bielekova B, Howard T, Packer AN, et al. Effect of anti-CD25 antibody daclizumab in the inhibition of inflammation and stabilization of disease progression in multiple sclerosis. Arch Neurol. 2009; 66(4): 483-489.

80. Tallantyre E, Evangelou N, Constantinescu CS. Spotlight on teriflunomide. Int MS J. 2008;15(2):62-68.

81. Salemi G, Callari G, Gammino M, et al. The relapse rate of multiple sclerosis changes during pregnancy: a cohort study. Acta Neurol Scand. 2004;110(1):23-26.

82. Vukusic S, Hutchinson M, Hours M, et al. Pregnancy and multiple sclerosis (the PRIMS study): clinical predictors of post-partum relapse. Brain. 2004; 127(Pt 6):1353-1360.

83. Sicotte ML, Liva SM, Klutch R, et al. Treatment of multiple sclerosis with the pregnancy hormone estiol. Ann Neurol. 2002;52(4): $421-428$. 
84. Soldan SS, Alvarez Retuerto AI, Sicotte NL, Voskul RR. Immune modulation in multiple sclerosis patients treated with the pregnancy hormone estriol. J Immunol. 2003;171(11):6267-6274.

85. Burt RK, Loh Y, Pearce W, et al. Clinical applications of blood-derived and marrow-derived stem cells for non-malignant disease. JAMA. 2008;299(8):925-936.

86. Muraro PA, Douek DC, Packer A, et al. Thymic output generates a new and diverse TCR repertoire after autologous stem cell transplantation in multiple sclerosis patients. $J$ Exp Med. 2005;201(5):805-816.

87. Nash RA, Bowen JD, McSweeney PA, et al. High-dose immunosuppressive therapy and autologous peripheral blood stem cell transplantation for severe multiple sclerosis. Blood. 2003;102(7): 2364-2372.

88. Burt RK, Cohen BA, Russell E, et al. Hematopoietic stem cell transplantation for progressive multiple sclerosis: failure of total body irradiation-based conditioning regimen to prevent disease progression in patients with high disability scores. Blood. 2003;102(7): 2373-2378.

89. Openshaw H, Lund BT, Kashyap A, et al. Peripheral blood stem cell transplantation in multiple sclerosis with busulfan and cyclophosphamide conditioning: report of toxicity and immunological monitoring. Biol Blood Marrow Transplant. 2000;6(5A): 563-575.

90. Fassas A, Passweg JR, Anagnostopoulos A, et al. Hematopoietic stem cell transplantation for multiple sclerosis. A retrospective multicenter study. J Neurol. 2002;249(8):1088-1097.

91. Carreras E, Saiz A, Marin P, et al. CD34+ selected autologous peripheral blood stem cell transplantation for multiple slcerosis: report of toxicity and treatment results at one year follow-up in 15 patients Haematologica. 2003;88(3):306-314.

92. Capello E, Saccardi R, Murialdo A, et al. Intense immunosuppression followed by autologous stem cell transplantation in severe multiple sclerosis. Neurol Sci. 2005;26 Suppl 4:S200-S203.

93. Xu J, Ji BX, Su L, Dong HQ, Sun XJ, Liu CY. Clinical outcomes after autologous haematopoietic stem cell transplantation in patients with progressive multiple sclerosis. Chin Med J (Engl). 2006;119(22): 1851-1855.

94. Mancardi GL, Saccardi R, Filippi M, et al. Autologous hematopoietic stem cell transplantation suppresses Gd-enhanced MRI activity in MS Neurology. 2001;57(1):62-68.

95. Sorensen PS, Mellgren SI, Svenningsson A, et al. NORdic trial of oral methylprednisoloine as add-on therapy to Interferon beta-1a for treatment of relapsing-remitting multiple sclerosis (NORMIMS study): a randomised, placebo-controlled trial. Lancet Neurol. 2009;8(6):519-529.

96. Ravnborg M, Sorensen PS, Andersson M, et al. Methylprednisolone in combination with interferon $\beta$-1a for relapsing-remitting multiple sclerosis (MECOMBIN study): a multicentre, double-blind, randomised, placebo-controlled, parallel-group trial. Lancet Neurol. 2010;9(7):672-680.

97. Cohen JA, Imrey PB, Calabresi PA, et al. Results of Avonex Combination Trial (ACT) in relapsing-remitting MS. Neurology. 2009;72(6): 535-541.

98. Havrdova E, Zivadinov R, Krasensky J, et al. Randomized study of interferon beta-1a, low-dose azathioprine, and low-dose corticosteroids in multiple sclerosis. Mult Scler. 2009;15(8):965-976.

99. Goodman AD, Rossman H, Bar-Or A, et al. GLANCE: results of a phase 2, randomized, double-blind, placebo-controlled study. Neurology. 2009;72(9):806-812.

100. Patti F, Amato MP, Filippi M, Gallo P, Trojano M, Comi GC. A double blind, placebo-controlled, phase II, add-on study of cyclophosamide (CTX) for 24 months in patients affected by multiple sclerosis on a background therapy with interferon-beta study denomination: CYCLIN. J Neurol Sci. 2004;223(1):69-71.

101. Correale J, Rush C, Amengual A, Goicochea MT. Mitoxantrone as rescue therapy in worsening relapsing-remitting MS patients receiving IFN-ß. J Neuroimmunol. 2005;162(1-2):173-183.
102. Ramtahal J, Jacob A, Das K, Boggild M. Sequential maintenance treatment with glatiramer acetate after mitoxantrone is safe and can limit exposure to immune-suppression in very active, relapsing remitting multiple sclerosis. J Neurol. 2006;253(9):1160-1164.

103. Conway D, Cohen JA. Combination therapy in multiple sclerosis. Lancet Neurol. 2010;9(3):299-308.

104. Schapiro RT. Managing symptoms of multiple sclerosis. Neurol Clin. 2005;23(1):177-187, vii

105. Loss of mobility found to impact quality of life and emotional and financial health of most people living with multiple sclerosis. National Multiple Sclerosis Society [news release on the Internet]. New York: National Multiple Sclerosis Society. March 2008, 25.Available from: http://www.nationalmssociety.org/news/news-detail/index. aspx?nid=199. Accessed Jun 12010 .

106. Bainbridge JL, Corboy JR. Multiple sclerosis. In: DiPiro JT, Talbert RL, Yee GC, Matzke GR, Wells BG, Posey LM, editors. Pharmacotherapy: A Pathophysiologic Approach. 7th ed. New York (NY): McGraw-Hill; 2008:913.

107. Judge SI, Bever CT Jr. Potassium channel blockers in multiple sclerosis: neuronal $\mathrm{Kv}$ channels and effects of symptomatic treatment Pharmacol Ther. 2006;111(1):224-259.

108. Korenke AR, Rivey MP, Allington DR. Sustained-release fampridine for symptomatic treatment of multiple sclerosis. Ann Pharmacother. 2008;42(10):1458-1465

109. Goodman AD, Brown TR, Krupp LB. Sustained-release oral fampridine in multiple sclerosis: a randomised, double-blind, controlled trial. Lancet. 2009;373(9665):732-738.

110. Goodman AD, Brown TR, Cohen JA, et al. Dose comparison trial of sustained-release fampridine in multiple sclerosis. Neurology. 2008;71(15):1134-1141.

111. Goodman AD, Cohen JA, Cross A, et al. Fampridine-SR in multiple sclerosis: a randomized, double-blind, placebo-controlled, doseranging study. Mult Scler. 2007;13(3):357-368.

112. Acorda Therapeutics. Acorda Therapeutics announces positive data from second Phase 3 study of fampridine-SR on walking ability in people with multiple sclerosis. Available from: http://phoenix. corporate-ir.net/phoenix.zhtml?c=194451\&p=irolnewsArticle \&ID= 1160986\&highlight. Accessed Jun 12010.

113. Acorda Therapeutics, Inc. Fampridine-SR Advisory Committee briefing document. Fampridine-SR tablets for improvement in walking ability in patients with multiple sclerosis. Peripheral and Central Nervous System Drugs Advisory Committee Meeting; 2009 Oct 14; NDA22-250. Available from: http://www.fda.gov/downloads/ AdvisoryCommittees/CommitteesMeetingMaterials/Drugs/ PeripheralandCentralNervousSystemDrugsAdvisoryCommittee/ UCM185664.pdf. Accessed Jun 202010.

114. Goodman AD, Brown T, Krupp L, et al. Interim analysis of an open-label extension study of sustained release fampridine in patients with multiple sclerosis [abstract]. Mult Scler. 2009; 15 Suppl 2:S13.

115. Goodman AD, Brown TR, Edwards KR, et al. Interim analysis of openlabel extension studies of dalfampridine extended release tablets in patients with multiple sclerosis [Abstract S01.008]. Proceedings of the American Academy of Neurology 2010 Annual Meeting; 2010 Apr 13; Toronto, Canada. Abstract available from: http:/www.abstracts2view. com/aan/view.php?nu=AAN10 L_S01.008. Accessed Jun 82010.

116. Schwid SR, Petrie MD, McDermott MP, Tierney DS, Mason DH, Goodman AD. Quantitative assessment of sustained-release 4-aminopyridine for symptomatic treatment of multiple sclerosis. Neurology. 1997;48(4):817-821.

117. Sanofi-Aventis. Efficacy, safety, and tolerability of nerispirdine in patients with multiple sclerosis. Last updated 2010 Mar 22. ClinicalTrials.gov Web site. Available from: http:/clinicaltrials.gov/ ct2/show/NCT00811 902. Accessed Apr 92010.

118. Smith C, Kongsamut S, Wang H, Ji J, Kang J, Rampe D. In vitro electrophysiological activity of nerispirdine, a novel 4-aminopyridine derivative. Clin Exp Pharmacol Physiol. 2009;36(11):1104-1109. 
119. Lange R, Volkmer M, Heesen C, Liepert J. Modafinil effects in multiple sclerosis patients with fatigue. J Neurol. 2009;256(4): 645-650.

120. Brown JN, Howard CA, Kemp DW. Modafinil for the treatment of multiple sclerosis-related fatigue. Ann Pharmacother. 2010;44(6): 1098-1103.

121. Stankoff B, Waubant E, Confavreux C, et al. Modafinil for fatigue in MS: a randomized placebo-controlled double-blind study. Neurology. 2005;64(7):1139-1143.

122. FDA approves Botox ${ }^{\circledR}$ for treating spasticity, or tightness, in upper limbs. National Multiple Sclerosis Society [news release on the Internet]. New York: National Multiple Sclerosis Society. 2010 Mar 12. Available from: http://www.nationalmssociety.org/news/news-detail/ index.aspx?nid=2875. Accessed May 172010.

123. Smith PF. New approaches in the management of spasticity in multiple sclerosis patients: role of cannabinoids. Ther Clin Risk Manag. 2010;6:59-63.

124. Christodoulou C, Melville P, Scherl WF, Macallister WS, Elkins LE, Krupp LB. Effects of donepezil on memory and cognition in multiple sclerosis. J Neurol Sci. 2006;245(1-2):127-136.
125. Shaygannejad V, Janghorbani M, Ashtari F, Zanjani HA, Zakizade N. Effects of rivastigmine on memory and cognition in multiple sclerosis. Can J Neurol Sci. 2008;35(4):476-481.

126. Morrow SA, Kaushik T, Zarevics P, et al. The effects of L-amphetamine sulfate on cognition in MS patients: results of a randomized controlled trial. J Neurol. 2009;256(7):1095-1102.

127. Lovera JF, Frohman E, Brown TR, et al. Memantine for cognitive impairment in multiple sclerosis: a randomized placebo-controlled trial. Mult Scler. 2010;16(6):715-723.

128. Kleinschnitz C, MEuth SG, Kieseier BC, Wiendl H. Immunotherapeutic approaches in MS: update on pathophysiology and emerging agents or strategies 2006. Endocr Metab Immune Disord Drug Targets. 2007;7(1):35-63.

129. Linker RA, Kieseier BC, Gold R. Identification and development of new therapeutics for multiple sclerosis. Trends Pharmacol Sci 2008;29(11):558-565.

\section{Publish your work in this journal}

Drug Design, Development and Therapy is an international, peerreviewed open-access journal that spans the spectrum of drug design and development through to clinical applications. Clinical outcomes, patient safety, and programs for the development and effective, safe, and sustained use of medicines are a feature of the journal, which has also been accepted for indexing on PubMed Central. The manuscript management system is completely online and includes a very quick and fair peer-review system, which is all easy to use. Visit http://www.dovepress.com/testimonials.php to read real quotes from published authors.

Submit your manuscript here: http://www.dovepress.com/drug-design-development-and-therapy-journal 